NBER WORKING PAPER SERIES

\title{
CAN COMPULSORY MILITARY SERVICE INCREASE CIVILIAN WAGES? EVIDENCE FROM THE PEACETIME DRAFT IN PORTUGAL
}

\author{
David Card \\ Ana Rute Cardoso \\ Working Paper 17694 \\ http://www.nber.org/papers/w17694 \\ NATIONAL BUREAU OF ECONOMIC RESEARCH \\ 1050 Massachusetts Avenue \\ Cambridge, MA 02138 \\ December 2011
}

We are grateful to two referees, and to Joshua Angrist and Patrick Kline for helpful comments. We also thank the Statistics Department of the Portuguese Ministry of Employment for access to the data. This research was supported by the Center for Labor Economics at UC Berkeley. Cardoso also gratefully acknowledges support from the Spanish Ministry of Science and Innovation (grant ECO2009-07958), the Spanish Ministry of Education (mobility grant PR2010-0004), and the Government of Catalonia. The views expressed herein are those of the authors and do not necessarily reflect the views of the National Bureau of Economic Research.

NBER working papers are circulated for discussion and comment purposes. They have not been peerreviewed or been subject to the review by the NBER Board of Directors that accompanies official NBER publications.

(C) 2011 by David Card and Ana Rute Cardoso. All rights reserved. Short sections of text, not to exceed two paragraphs, may be quoted without explicit permission provided that full credit, including $\odot$ notice, is given to the source. 
Can Compulsory Military Service Increase Civilian Wages? Evidence from the Peacetime

Draft in Portugal

David Card and Ana Rute Cardoso

NBER Working Paper No. 17694

December 2011

JEL No. J24,J31

\begin{abstract}
Although military conscription was widespread during most of the past century, credible evidence on the effects of mandatory service is limited. We provide new evidence on the long-term effects of peacetime conscription, using longitudinal data for Portuguese men born in 1967. These men were inducted at a relatively late age (21), allowing us to use pre-conscription wages to control for ability differences between conscripts and non-conscripts. We find that the average impact of military service for men who were working prior to age 21 is close to zero throughout the period from 2 to 20 years after their service. These small average effects arise from a significant 4-5 percentage point impact for men with only primary education, coupled with a zero-effect for men with higher education. The positive impacts for less-educated men suggest that mandatory service can be a valuable experience for those who might otherwise spend their careers in low-level jobs.
\end{abstract}

\author{
David Card \\ Department of Economics \\ 549 Evans Hall, \#3880 \\ University of California, Berkeley \\ Berkeley, CA 94720-3880 \\ and NBER \\ card@econ.berkeley.edu \\ Ana Rute Cardoso \\ IAE (CSIC) and Barcelona GSE \\ 08193 Bellaterra \\ Barcelona \\ Spain \\ anarute.cardoso@iae.csic.es
}




\section{Introduction}

Throughout the 20th Century young men in most Western countries faced the risk of military conscription. Although compulsory service ended in the U.S. in 1973, the practice continued until very recently in many European nations, and is still widely used around the world. ${ }^{1}$ Spurred in part by recent decisions to end conscription in Sweden, Italy, France, and Germany, there is renewed interest in understanding the impacts of mandatory service on a wide range of outcomes, including earnings (Angrist and Chen, 2011; Angrist, Chen, and Song, 2011; Grenet et al., 2011; Paloyo, 2010), education (Maurin and Xenogiani, 2007; Cipollone and Rosolia, 2007; Keller et al., 2009; Bauer et al., 2009), health (Bedard and Deschenes, 2006; Dobkin and Shabani, 2009; Autor et al., 2011), and crime (Galiani et al., 2011).

Revealed preference arguments suggest that conscripts will suffer economic losses from coerced service (e.g., Oi, 1967). Nevertheless, some analysts have argued that compulsory service can have a positive return for disadvantaged youth who face limited civilian job opportunities (e.g., Berger and Hirsch, 1983; de Tray, 1982). ${ }^{2}$ Seminal research by Angrist (1990) showed that Vietnam-era draftees had lower earnings than non-draftees, a finding he attributed to the low value of military experience in the civilian labor market. Subsequent research in the U.S. and other countries, however, has uncovered a surprisingly mixed pattern of impacts. Imbens and van der Klaauw (1995) found that 10 years after conscription Dutch veterans earned lower wages than those who avoided service. In contrast, Albrecht et al. (1999) estimated a positive earnings premium for Swedish conscripts. Grenet et al. (2011) find no long-run impact on the wages of British conscripts; likewise, Bauer et al. (2009) find no effect for West German conscripts. ${ }^{3}$ In a recent re-analysis of the Vietnam-era draftees, Angrist and Chen (2011) find that by age 50 they have about the same earnings as non-draftees, and slightly higher education.

In this paper we present new evidence on the long-run effects of mandatory military service, using detailed longitudinal data for Portuguese men born in the late 1960s.

\footnotetext{
${ }^{1}$ In Europe, for example, Austria, Denmark, Estonia, Finland, Greece, Norway, and Switzerland all still require men to perform some form of national service. Russia and China also have mandatory military service.

${ }^{2}$ Hirsh and Mehay (2003) study wage differences between reservists who have served in active duty and those who have not, and find small average differences, but a positive impact of service for African Americans.

${ }^{3}$ Kunze (2002) analyzes longitudinal data for German workers and finds a complex pattern of earnings premiums for veterans.
} 
Some $40 \%$ of the men in these cohorts served in the military: a majority entered the service with less than 6 years of formal schooling. Our analysis relies on a unique annual census of wages - the Quadros de Pessoal (QP) - that allows us to track the cohorts of interest from their initial entry into the labor market until their early forties. Using the fact that employers were required to treat conscripted employees as being on leave of absence, we can identify men who were working just prior to the age of conscription (age 21) and then entered the military, and a comparison group of men who remained in civilian jobs over the same period.

Implementing a series of difference-in-differences estimators we find that the average impact of military service for men who had entered the labor market by age 21 is positive but insignificantly different from zero throughout the period from 2 to 20 years after their service. This small average effect, however, masks a statistically significant later-life impact of about 4-5\% for men with lower levels of education (under 6 years of schooling), coupled with a zero-effect for men with higher education. The positive impact for the less-educated group mirrors the findings for U.S. veterans by Berger and Hirsch (1983) and suggests that mandatory service can be a valuable experience for disadvantaged men who might otherwise spend their careers in low-level jobs. Our confidence in these results is bolstered by three additional findings. First, we find that wages of the men who eventually served in the military and those who did not track each other very closely in the period up to age 21 . Second, we find that pre-conscription wages are a strong predictor of wages 10 to 20 years later, suggesting that any differences in average ability between veterans and non-veterans are revealed by their wages in the period prior to conscription. Third, comparisons of employment rates show that the veterans converge to the non-veterans within about 6-7 years after the completion of service, alleviating concerns about possible selection biases.

While our primary focus is on the effect of conscription for men who were working prior to age 21, an important concern is that conscription could have had different effects on other groups - e.g., those who never worked prior to age 21. As a check we relate average wages for men born in different years from 1959 to 1969 to cohort-level data on conscription rates. Consistent with our main findings, this analysis points to a small positive average effect of conscription, and rules out a large negative average effect across all the men in a particular cohort.

The next section of the paper provides a brief overview of the institutional background underlying the conscription process in Portugal in the late 1980s. Section 2 
discusses the QP data set and our method for identifying conscripts, based on unpaid leave-of-absence status. We then provide a comparison of the conscript and non-conscript groups, as well as other individuals in the birth cohort under analysis. Section 4 presents the details of our statistical approach, which takes advantage of the availability of preconscription earnings data to control for potential ability differences between conscripts and non-conscripts. Section 5 presents our main findings, first using graphical techniques, then using more formal regression models, including models that explore a range of possible values for the relative effect of unobserved ability in pre-conscription versus post-conscription earnings. We also explore possible mechanisms driving the enlistment effect. Section 6 presents our inter-cohort comparisons for men born between 1959 and 1969, while section 7 concludes.

\section{Military Service in Portugal}

During the 1960s and early 1970s Portugal fought colonial wars in Angola, Mozambique, and Guinea-Bissau staffed by a far-reaching conscription system. ${ }^{4}$ Following the overthrow of the Estado Novo regime in 1974 and the withdrawal from Africa, the Portuguese military transitioned to a smaller peacetime force. ${ }^{5}$ Throughout the $1980 \mathrm{~s}$ and early 1990s men were at risk of conscription in the year they turned 21, and draftees were required to serve for a maximum of 2 years. ${ }^{6}$ Individuals were called for medical and psychological evaluations in the year they turned 20. Those judged physically or mentally unfit and those convicted of serious felonies were exempted from service. A tiny fraction of men (some 100 to 300 per year) also met the substantial hurdles to qualify for alternative service as conscientious objectors (Domingues, 1998). Short-term deferments could be granted to students and individuals who were the sole providers for their family, but options for self-selecting out of service altogether were quite limited.

Over the 1990s a series of laws reduced the age of conscription to 20 (effective in 1993 for men born in 1973 or later) and reduced the duration of service to a maximum of 8 months for the 1970 and 1971 birth cohorts, and to 4 months for those born in 1972 or later. Finally, in 2005, peacetime conscription ended and the Portuguese military

\footnotetext{
${ }^{4}$ By the early 1970s some $8 \%$ of the Portuguese labor force were in the military (Graham, 1979). A relatively large number of young people - over 100,000 per year in 1970, for example - left the country illegally to avoid service (Baganha and Marques, 2001, Table 2.10).

${ }^{5}$ Carrington and de Lima (1996) study the impact of the large number of retornados - Portuguese nationals who returned at the end of the colonial wars - on labor market conditions in Portugal.

${ }^{6}$ Information on the terms of service for men who served in the 1980 s and 1990 s is taken directly from legal statutes: see the Appendix for a list of these laws.
} 
became an all-volunteer force open to both men and women.

Table 1 presents a variety of data on the conscription system facing Portuguese men born from 1959 to 1979, including the size of each cohort, the age of determination of conscription status, the number of men drafted in the year the cohort reached the age of conscription, the fraction of the cohort who were conscripted, and their maximum length of service. The conscription rate for men born in the 1960s and 1970s ranged from 30 to 50 percent, with a dip for the 1972 and 1973 cohorts who were both subject to the draft in 1993. Note that unlike the situation in some European countries, peacetime service in Portugal was far from universal. Instead, the fraction of men who served in a given cohort was determined by the manpower needs of the military, the duration of service, and the size of the cohort.

Once in the military, conscripts with the lowest levels of education could undertake basic skills training while those with higher schooling could undertake occupational training. Labor laws in Portugal specify that occupational training acquired in the military is equivalent to civilian training, allowing some conscripts to accumulate transferable skills. ${ }^{7}$ Another important piece of legislation required employers to treat drafted men as "on leave" from their job. This provision may have discouraged firms from hiring young men until their conscription status was settled, though as we discuss below we see no evidence of this behavior. For those who were hired and subsequently drafted, however, it presumably eased the transition back to civilian life. Finally, conscripts in good standing could re-enlist for up to 8 years of additional service, though re-enlistment rates were generally quite low.

\section{Data on Earnings and Conscription Status}

\section{The Quadros de Pessoal}

Our analysis relies on a unique administrative data set, the Quadros de Pessoal (QP), collected annually by the Ministry of Employment. The QP is a census of paid workers in the Portuguese private sector: all firms with at least one paid worker are legally obligated to return information on their full roster of employees, including wages and hours of work during the appropriate reference week (in March until 1993 and in October since 1994). ${ }^{8}$ Importantly for our purposes, during the 1980s and 1990s the QP asked em-

\footnotetext{
${ }^{7}$ Currently, such equivalence is guaranteed for training in such fields as professional driving, cooking and bakery, and emergency medical support.

${ }^{8}$ Firms are required to post their employee rosters and the corresponding salary information in a public place visible by its workers, helping to ensure the accuracy of the reported infor-
} 
ployers to include men on leave for military duty in their roster. We identify individuals with missing values for their earnings and hours of work in the reference week as being "on leave". ${ }^{9}$ A limitation of the data is that government workers - who comprise just under 20 percent of the Portuguese workforce - are excluded from coverage. ${ }^{10}$ A second limitation is that the QP provides only a snapshot of labor market outcomes in each year. Individuals who are unemployed or out of the labor force at the time of the census have no labor market data for that year. Electronic records from the QP are available for the period from 1986 to 2009, and include worker and firm identifiers that allow individuals to be tracked over time and across jobs. Worker-level data are unavailable for 1990 and 2001, creating gaps in the worker histories in those two years.

Information for employees in the QP includes gender, date of birth, current educational attainment, occupation, date of hire, base earnings, supplemental payments, and hours of work. Information on the employer side includes industry and location of the firm, gross annual revenues, and ownership status. We use an edited version of the data that has been checked for consistency of the longitudinal matches (see the Data Appendix). We measure a worker's gross hourly wage by dividing the sum of the individual's monthly base-wage and other regularly-paid benefits by his or her normal hours of work. ${ }^{11}$ All wages are deflated using the Consumer Price Index (2009=100). We treat as missing any wage observation that is below 0.75 of the first percentile of wages, or above 3 times the 99 th percentile, in the corresponding year. This eliminates a small fraction (about 1\%) of observations that appear to reflect misplaced decimals and similar gross errors.

\section{Identifying Conscripts}

Ideally we could combine information from military records with labor market data from the QP to study the impacts of service on all veterans, including men with no record of employment prior to conscription. Unfortunately, individual military service records

mation. During the 1980s there was some under-coverage in the QP, particularly of small firms (Braguinsky et al., 2011).

${ }^{9}$ Firms may also fail to report earnings and hours for other reasons, including long-term illnesses, strikes, and maternity leave - see Table A.1 in the Data Appendix. Unfortunately, the reason for leave status is not available in the electronic version of the QP.

${ }^{10}$ Also missing from the employee rosters are contract workers. In recent years such workers have accounted for a growing share of employment (Rebelo, 2003).

${ }^{11}$ Reported earnings are net of the employer portion of social security taxes, but include the employee portion of the tax, currently 11 percent. For a fraction of workers the employer's report of hours appears to depend on the number of days worked in the survey month, which varies from year to year. All our models include year effects to control for this variation. 
are not available. Thus, we have to infer conscription status from the observed data in the QP. We focus on men born before 1970 (when the maximum term of service was reduced to 8 months), and make use of the fact that employers were instructed to report workers who had been drafted as on leave. A complication is that some of the conscripts in a given year could be inducted early in the year, before the March date of the QP, and others could be inducted after the QP was completed. We therefore identify two separate groups of conscripts: (1) men who are recorded in the QP as working full time in March of the year they turned 20 years of age, and are "on leave" (i.e., reported with missing earnings and hours) in the next two years; (2) men who were working full time in March of the year they turned 21, and were on leave in March in the next year. ${ }^{12}$ As a comparison group we use men who were working full time in March of the year they turned 21 and in March of the following year. These men could not have been inducted into the military at age 21 and served more than a year. Note that we are limiting attention to conscripts and non-conscripts who were working just before or just after reaching the age of 21 . This has the important advantage that we have a full-time wage observation for each person at (approximately) age 21. For conscripts, the wage is measured just prior to entering the military at age 20 or 21 ; for non-conscripts, it is measured in the year they turn 21 .

To implement these definitions we need to limit attention to cohorts that reached the age of 20 in 1986 or later (the first year QP data are available). Moreover, since the QP has a gap in 1990, we cannot use data for cohorts born in 1968 or 1969, as their status in the years they turned 21 or 22 is unknown. Given these constraints, we focus on men born in 1967 as our primary cohort of interest. These men were 18 or 19 at the time of the first available QP survey in March 1986 and can be followed continuously for three years until the break in the data in 1990 (i.e., until March 1989, when they were 21 or 22 years of age). In particular for this cohort we have at least two years of data on wages prior to the age at which their conscription status was determined.

Before proceeding further it is important to verify that men born in 1967 who were working full time at age 20 or 21 and then recorded as on leave were actually conscripted. While we cannot offer definitive proof, we conducted a series of comparisons summarized in Figure 1 that we believe are highly supportive of our assumptions. The upper left

\footnotetext{
${ }^{12}$ As a robustness check we consider relaxing the criteria for the first subgroup slightly by requiring that they were employed full time in March of the year they turned 20 and on leave in the next March. We show below this has very little effect on our results.
} 
hand panel of the figure shows the distribution of activities in each year of age from 18 to 42 for men born in 1967 who were observed working full time at either age 20 or 21 . Notice that the fraction of the cohort reported on leave is relatively high for only two years - ages 21 and 22. Moreover, the total fraction observed working or on leave at ages 21 and 22 is very similar to the fraction observed working at ages 23 and older. This pattern strongly suggests that leave of absence status is associated with military service. By comparison, the upper right hand panel shows similar data for women born in 1967. For women there is no "unusual" spike in the fraction on leave at ages 21 and 22 , confirming that the draft is the likely explanation for the high fraction of men on leave at these ages.

Comparisons with later cohorts of men and women, presented in the middle and lower panels of the Figure, provide further evidence that most of the men from the 1967 cohort who were on leave at ages 21-22 were in the military. In the middle panels we show data for people born in 1977 who were observed working full time at age 19 or 20. (We adjust the requirement on age to reflect the fact that conscription occurred at age 20 for this cohort). Consistent with the very short term of military service for this cohort (4 months maximum) we see only a relatively small rise in the fraction of men classified as on leave at age 20. For women born in 1977 the patterns look very similar to those of women born 10 years earlier. Finally, in the lower panels of Figure 1 we show data for men and women born in 1987 who were observed working full time at age 19 or 20. For this cohort there was no mandatory military service, and reassuringly only a very small fraction of men are recorded as on leave between the ages of 20 and 22 . Again, the data for women look relatively similar to the data for women born 10 or 20 years earlier.

While we believe that military service accounts for the unusual spike in the fraction of 1967 men on leave at ages 21 and 22, some men would obviously fall into this category even in the absence of conscription. To estimate the "false positive" rate we tabulated the fractions of men at different ages who were working in the $1988 \mathrm{QP}$ and on leave in 1989. This fraction was $19.0 \%$ for 21 year olds, $9 \%$ for 22 year olds, $3.0 \%$ for 23 year olds, and between $2.7 \%$ and $3.0 \%$ for men between the ages of 24 and 30. Comparing 21 year olds to those 23 and older, we infer that about $15 \%$ of 21 -year-olds were probably on leave for other reasons. This means that simple comparisons between men identified as conscripts and those identified as non-conscripts will likely understate the magnitude of the true gap by about $15 \%$. 


\section{The 1967 Birth Cohort: Conscripts, Non-Conscripts, and Others}

While we can use employment and leave status information to identify a group of men born in 1967 who were working just before the determination of their conscription status and served in the military, and a comparison group who did not serve, there are many others in the cohort whose draft status is uncertain, including men with no record of employment by age 21 . Table 2 presents some comparative information on the various subgroups to help contextualize our main groups of interest.

Out of the full cohort of approximately 104,000 men born in 1967 (see Table 1), approximately $90 \%$ are observed as private-sector employees in the QP at some point between 1986 and 2009. Of these, about 5\% have some inconsistency in their data (i.e., a missing or outlier wage observation if employed, or a problem linking records over time). Deletion of these observations leads to a sample of 86,909 men born in 1967 and ever observed in the QP with valid data, summarized in column 1 of Table 2. Given the low schooling attainment of this cohort (mean completed school at age $35=7$ years) most of the men were presumably out of school by age 19. Nevertheless only about one-fifth were working full time at age 20 or 21 and meet the criteria to be potentially used in our analysis. ${ }^{13}$ Despite the relatively low fraction working before age 21 , the bottom rows of the table show that $61 \%$ are observed at least once between 2002 and 2009 (at ages 35-42).

Column 2 shows the characteristics of the entire sample of "early labor market entrants" (i.e., those who were working full time at age 20 or 21). Interestingly, the fraction of this subgroup observed in the QP at least once between 2002 and 2009 is very similar to the fraction of the entire cohort observed in that interval (62\% versus $61 \%$ ), while the average wages of the early labor market entrants are about $12 \%$ lower than the average wage for the entire cohort. We suspect that most of the difference is attributable to the relatively lower schooling of the early labor market entrants. By 2002, their average years of completed schooling was 5.8 years, versus 7.1 years for the cohort as a whole.

\footnotetext{
${ }^{13} \mathrm{~A}$ concern about the legal requirement that draftees be allowed to return to their job at the end of their service is that this would discourage employers from hiring men before the age of 21. We conducted a difference in differences analysis of employment rates of men and women at ages 18, 19, and 20 between cohorts born in 1967 and those born in 1987, testing whether the employment rates of the 1967 cohort of men were unusually low. This shows a small male $\times 1967$ interaction effect (around -1.5 percentage points) potentially indicating a small discouragement effect in the hiring of men when the draft was in effect.
} 
Among the early labor market entrants we identify four subgroups: conscripts (column 4 of Table 2), who were either working full time in March 1987 and on leave the next two years, or working full time in March 1988 and on leave the next year; non-conscripts (column 5), who were working full time in both March 1988 and March 1989; people missing from the QP in 1989 (column 6) who were presumably unemployed, out of the labor force, or working in the government sector in March 1989; and finally a fourth residual group (column 7 ) made up of men with a variety of employment histories in the period from 1987 to 1989 that do not fit into the other 3 groups. Both the missing and residual groups include a mix of conscripts and non-conscripts. For example, men who were working full time in March 1988 but subsequently left that job before entering the military later in the year would appear in the "missing" group.

Comparisons across columns 4-7 show that the 1986-88 wages of the conscripted and non-conscripted groups are quite similar, while the wages of the group who are missing from the $1989 \mathrm{QP}$ are a little lower, and those of the residual group are a little higher. The conscripts have the highest education levels of the four groups of early entrants, measured either in the first year they ever appear in the QP, or in 2002. Anecdotal evidence suggests that the military generally preferred men with higher literacy and numeracy skills, leading to a systematic under-representation of the lowest educated men in the conscripted group. Nevertheless, conscripts and non-conscripts have nearly the same probability of appearing in the QP in the period from 2002 to 2009, and fairly similar hourly wages. Interestingly, the group who were missing from the QP in 1989 have a much lower likelihood of appearing in the data set during 2002-2009, suggesting strong persistence in their low probability of private-sector employment. The residual group, by comparison, has about the same likelihood of appearing in the QP in the 2002-2009 period as the conscripts and non-conscripts.

Finally, column 8 of Table 2 shows data for the men who were not working full time in either 1987 or 1988 . Some of these late labor market entrants were attending postsecondary schooling at age 20-21. Consistent with this fact, the fraction of the group with a university degree is relatively high (though still only $8 \%)^{14}$, and on average they have two more years of education than the early labor market entrants. Despite their late entry to the labor market, by mid-career they are about as likely to appear in the QP as the early entrants group (61\% with a wage observation between 2002 and 2009 , versus $62 \%$ for early entrants as a whole). By this time they also have about $17 \%$

\footnotetext{
${ }^{14} \mathrm{~A}$ larger share attended college, given that the drop-out rate is approximately $30 \%$.
} 
higher average wages than the early entrants (mean log wage $=1.71$ versus 1.54 for early entrants), reflecting their nearly 2 additional years of schooling.

In the remainder of the paper we mainly focus on comparisons between early entrants who can be clearly identified as conscripts (column 4 of Table 2) and those who can be clearly identified as non-conscripts (column 5). In Section 5, however, we present a series of robustness checks in which we consider relaxing the criteria to be included in the conscript and non-conscript groups, thereby moving some of the men from the missing and residual categories into these groups. As we show, plausible changes in the definitions of the two groups have little impact on our main results. In section 6 we use cohort-wide comparisons of wages and conscription rates for men born from 1959 to 1969 to assess the magnitude of the conscription effect estimated for the subgroup of early labor market entrants in 1967.

\section{Measuring the Causal Effect of Conscription on Subse- quent Earnings}

Given the non-random nature of the conscription process facing men born in the 1960s in Portugal, a fundamental concern for our analysis is that unobserved differences between veterans and non-veterans will confound our estimate of the effect of military service. Anecdotal evidence, for example, suggests that many men were exempted from service for health-related reasons that might also affect their future wages. ${ }^{15}$ Since our primary focus in on men who were working full time just prior to determination of their conscription status, we use pre-conscription wages to control for ability differences between veterans and non-veterans. Our approach is essentially a difference-in-differences framework, generalized to allow the return to unobserved ability to increase with age.

To proceed more formally, let $S$ denote the level of schooling of a given individual at the date just before the conscription decision is made. (For notational simplicity we treat $S$ as a number: in our empirical analysis, however, we measure education with a set of dummies). We assume that $S$ is a function of a general measure of ability $a$ and a random error component $u_{1}$ :

$$
S=f(a)+u_{1}
$$

where $f()$ is a possibly nonlinear function. Let $w_{0}$ represent the logarithm of the hourly wage that is earned by the individual just prior to the determination of conscription

\footnotetext{
${ }^{15}$ Tartter (1993) reports that in 1989 one quarter of potential conscripts were deemed physically unfit for service.
} 
status. We assume that this wage depends on ability, schooling, and an additive error component $\epsilon_{0}$ that is uncorrelated with schooling:

$$
w_{0}=a+\gamma_{0} S+\epsilon_{0}
$$

Note that we have scaled the ability measure by assuming that expected log wages in period 0 vary 1 for 1 with $a$ (holding constant schooling). Assume that the probability of being conscripted into the military (indicated by the binary variable $V$ ) is a general function of ability and schooling, but does not depend on the transitory error $\epsilon_{0}$ :

$$
\operatorname{pr}(V=1)=h(a, S) .
$$

Finally, assume the wage in post-service period $t=1, \ldots T$ depends on an additive function of ability, schooling, enlistment status, and an error component $\epsilon_{t}$ :

$$
w_{t}=\psi_{t} a+\gamma_{t} S+\theta_{t} V+\epsilon_{t}
$$

where $\psi_{t}>0$ is a loading factor that can vary over time, $\theta_{t}$ represents the causal effect of military service on wages in period $t$, and the error term $\epsilon_{t}$ is assumed to be uncorrelated with ability, schooling, or veteran status (though $\epsilon_{t}$ may be correlated with $\epsilon_{t-j}$ ).

If conscription status is correlated with ability, OLS estimation of equation (2) will lead to a biased estimate of the causal effect $\theta_{t}$. When $\psi_{t}=1$ this correlation can be eliminated by comparing the growth rates of wages of veterans and non-veterans, leading to a difference-in-differences specification:

$$
w_{t}-w_{0}=\left(\gamma_{t}-\gamma_{0}\right) S+\theta_{t} V+\epsilon_{t}-\epsilon_{0}
$$

Though the assumption that unobserved ability has a constant effect on wages is a natural starting point, a number of studies have found that the return to ability rises with experience as market participants learn about the true abilities of different individuals. ${ }^{16}$ Schoenberg (2007, Table 5), for example, shows that the effect of measured AFQT scores on wages of men in the NLSY roughly doubles during their first decade in the labor market, suggesting a value of $\psi_{t} \approx 2$ for $t=10 .^{17}$

\footnotetext{
${ }^{16}$ See for example Farber and Gibbons (1996) and Altonji and Pierret (2001). The same point has arisen in studies that attempt to use income measured at a certain point as a proxy for permanent income - see Haider and Solon (2006).

${ }^{17}$ Similar analyses have also been conducted using the same data set by Lange (2007), and Arcidiacono et al. (2008). All these studies show a rise in the return to AFQT in the first 10 years in the labor market, particularly for men without a college education.
} 
To illustrate the more general case $\left(\psi_{t} \neq 1\right)$, we follow Chamberlain (1982) and consider the linear projection of unobserved ability on schooling and veteran status:

$$
a=\pi_{s} S+\pi_{v} V+\eta
$$

where $E[\eta S]=E[\eta V]=0$. Substituting this equation into (1) and (2) yields the reduced form system:

$$
\begin{aligned}
w_{0} & =\left(\pi_{s}+\gamma_{0}\right) S+\pi_{v} V+\eta+\epsilon_{0} \\
& =b_{S 0} S+b_{V 0} V+v_{0} \\
w_{t} & =\left(\psi_{t} \pi_{s}+\gamma_{t}\right) S+\left(\psi_{t} \pi_{v}+\theta_{t}\right) V+\psi_{t} \eta+\epsilon_{t} \\
& =b_{S t} S+b_{V t} V+v_{t}
\end{aligned}
$$

The reduced form effect of veteran status on pre-conscription wages $\left(b_{V 0}\right)$ provides an estimate of the ability gap between conscripts and non-conscripts, $\pi_{v}$. The reduced-form effect in any later period, $\left(b_{V t}\right)$, includes the true causal effect $\theta_{t}$ and a bias term that depends on the ability gap (measured in period 0 units) and the return to ability in period $t$. Given estimates of $b_{V 0}$ and $b_{V t}$, and a value for the relative factor loading $\psi_{t}$, an unbiased estimate of the causal effect of veteran status in period $t$ is:

$$
\widehat{\theta}_{t}=\widehat{b}_{V t}-\psi \widehat{b}_{V 0}
$$

In a "balanced" sample with no missing wage data an identical estimate can be obtained by forming a quasi-difference in wages between period $t$ and period 0 and regressing the outcome on schooling and veteran status:

$$
w_{t}-\psi_{t} w_{0}=\left(\gamma_{t}-\psi_{t} \gamma_{0}\right) S+\theta_{t} V+\epsilon_{t}-\psi_{t} \epsilon_{0}
$$

Note that when $\widehat{b}_{V 0}=0$ there is no measured ability difference between veterans and non-veterans, and different choices for the quasi-differencing factor $\psi_{t}$ will yield the same estimate of $\widehat{\theta}_{t}{ }^{18}$ In the analysis below we show that estimates of $\widehat{b}_{V 0}$ for men who were working full time prior to the age of conscription are uniformly small and statistically insignificant, suggesting that the ability differences are negligible.

Despite the relatively small estimates of $\widehat{b}_{V 0}$ in our sample, when $\psi$ is large in magnitude the bias correction implied by equation (5) can be sizeable. It is therefore

\footnotetext{
${ }^{18}$ In the case where $\widehat{b}_{V 0}=0$ different choices for $\psi$ will lead to identical estimates for $\theta_{t}$ but the sampling error will vary with the choice of $\psi$.Assuming $\widehat{b}_{V 0}=0$ the most efficient choice for $\psi$ is the estimated coefficient of $w_{0}$ from an OLS regression of $w_{t}$ on $S, V$, and $w_{0}$.
} 
interesting to ask what value of $\psi$ is appropriate for our setting. Unfortunately, without additional restrictions the set of factor loadings, returns to schooling, and returns to veteran status $\left\{\psi_{t}, \gamma_{t}, \theta_{t}\right\}$ are not identifiable from the $2(T+1)$ reduced-form regression coefficients in equations (3) and (4). One potential set of identifying assumptions is that the returns to schooling and veteran status are both constant over time (i.e., $\gamma_{t}=\gamma_{0}=\gamma$ and $\theta_{t}=\theta$ ). In this case, if there are at least two post-conscription periods with different $\psi_{t}^{\prime} s$ (both not equal to 1 ), it is possible to obtain estimates of the loading factors and the veteran effect $\theta$ using the relative changes in the reduced form effects of schooling and veteran status between periods. In the Portuguese context there is considerable evidence that the return to education has risen over the past two decades (e.g., Centeno and Novo, 2009). Moreover, existing research suggests that the premium for veteran service may change with age or experience (e.g., Angrist, 1990 and Angrist and Chen, 2011). Thus, we do not pursue this identification strategy here.

An alternative identification strategy uses the second moments of the reduced form errors in equations (3) and (4):

$$
v_{t}=\psi_{t} \eta+\epsilon_{t} \quad t=0,1, \ldots T
$$

with $\psi_{0}=1$ (see Lemieux, 1998). This "one factor" model implies a highly restrictive covariance structure:

$$
\begin{aligned}
\operatorname{var}\left[v_{t}\right] & =\left(\psi_{t}\right)^{2} \operatorname{var}[\eta]+\operatorname{var}\left[\epsilon_{t}\right] \\
\operatorname{cov}\left[v_{t}, v_{s}\right] & =\psi_{t} \psi_{s} \operatorname{var}[\eta]+\operatorname{cov}\left[\epsilon_{t}, \epsilon_{s}\right] .
\end{aligned}
$$

Given a data generating process for the transitory shocks $\epsilon_{t}$ and a parametric shape for the time path of the loading factors, the key parameters $\psi_{t}$ can be estimated by minimum distance methods from the observed covariances of the reduced form wage residuals $\widehat{v}_{t}$ $(t=0,1 \ldots T)$. In the Appendix we describe how we apply this procedure to obtain estimates of the $\psi_{t}^{\prime} s$ for the men in our sample of veterans and nonveterans who were working at age 20/21. In brief, we assume that the transitory shocks $\epsilon_{t}$ are generated by a stationary first-order autogressive process, with an arbitrary initial condition. We also assume that $\psi_{t}$ rises linearly for $\bar{t}$ years, and then stabilizes:

$$
\begin{array}{rlr}
\psi_{t} & =1+g t & 0 \leq t \leq \bar{t} \\
& =\bar{\psi}=1+g \bar{t} & t>\bar{t} .
\end{array}
$$

This path is roughly consistent with the path implied by standard learning models (e.g., 
Farber and Gibbons, 1996), assuming that learning is completed after $\bar{t}$ years. ${ }^{19}$ Some experimentation revealed that a value of $\bar{t}$ equal to 14 years yields the best fit to the data, and leads to a value of $\bar{\psi}=2.62$ (standard error $=0.16$ ), which is comparable to the estimate obtained by Schoenberg (2007) for the rise in returns to AFQT. The estimated variance components imply that $78 \%$ of the variance in pre-conscription wages is attributable to the transitory shock, and that the transitory wage shocks have a firstorder autocorrelation coefficient of 0.72 .

Although models like (1) and (2) are widely used in the program evaluation literature, there are a number of concerns with a simple difference-in-differences framework for measuring the effect of conscription in Portugal. One is that veteran status may be correlated with both the permanent component of ability and the transitory error in pre-conscription earnings. In this case, veterans and non-veterans with similar perconscription wages would not be expected to follow the same wage trajectory in the absence of a true service effect. One way to test whether veteran status is independent of the transitory wage component is to examine a longer series of pre-conscription earnings, and look for a "dip" or "surge" in wages just prior to conscription (e.g., Ashenfelter, 1978, Ashenfelter and Card, 1985). As we show below, wages of the conscipts and nonconscripts follow very similar trends in the three years prior to conscription, providing no evidence that men with temporarily low (or high) wages were more likely to be conscripted.

A second concern is that wages of young workers in Portugal may be relatively uninformative about long run ability differences because of institutional forces that compress wage differentials at the low end of the wage distribution - specifically, mandatory coverage by sectoral bargaining contracts, and a high minimum wage (see for example, Cardoso, 1998; Cardoso and Portugal 2005; Centeno and Novo, 2009). Despite these institutional forces, wages at age 20/21 are highly predictive of wages later in life for the men in our sample. This fact is illustrated in Figure 2, where we plot mean log wages in 2002-2009 against mean log wages at age 20-21 for the men in 100 "percentile groups", classified by the value of their pre-conscription wages. (We use the combined sample of 6,749 conscripts and non-conscripts described in column 3 of Table 2 to construct the figure). Two features are notable in this graph. The first is that hourly wages at age $20 / 21$ are relatively disperse. In particular, less than $2 \%$ of workers earn the hourly

\footnotetext{
${ }^{19}$ Altonji and Pierret (2001) and Schoenberg (2007) consider models in which the return to AFQT is allowed to rise linearly with experience, and also consider quadratic models.
} 
equivalent of the national minimum wage at age $20 / 21$, and there are no other large "spikes" in the distribution, so intial wages for all 100 percentile groups are distinct. ${ }^{20}$ A second observation is that the relationship between wages at 20/21 and average wages in mid-career is quite strong. The correlation across percentile groups is 0.87 , implying that three-quarters of the variation in average wages at ages 35-42 for groups of size $n \approx 67$ can be predicted from average wages at age $20 / 21 .^{21}$

\section{The Effect of Conscription on Subsequent Wages}

\section{Graphical Overview}

To set the stage for our main results it is helpful to begin with a graphical overview of the wage and employment outcomes of early labor market entrants who were either conscripted or not conscripted. Figure 3a plots the wage profiles for the two groups. In this graph, and in our subsequent regression models, we classify observations by the calendar year of observation in the QP, and report mean log wages for all observations with a wage in that year. Note that the absence of data for 1990 and 2001 creates "holes" in the profiles in these years. Taking account of these gaps we have up to three years of pre-conscription wage data (in 1986, 1987, and 1988) $)^{22}$ and up to 18 years of post-conscription data (for 1991 to 2009).

Examination of the wage series in Figure 3a shows that the pre-conscription wage profiles are very similar for the two groups, with a small positive wage advantage for conscripts in each year. In particular the wage profiles are virtually parallel and show no evidence of a pre-treatment dip or surge for conscripts relative to those who were not conscripted. This pattern is consistent with the assumption that selection into the military was driven by the permanent characteristics of workers, rather than the transitory wage outcome at age 20 or 21 . In 1991, the first year of the post-service period, the two groups again have very similar wages. Thereafter, wages of the conscripts are uniformly above those of the non-conscripts, with a 1-3 percentage point gap between

\footnotetext{
${ }^{20}$ Minimum wage legislation in Portugal specifies a minimum for monthly earnings: about $7 \%$ of the sample are recorded as earning the minimum monthly earnings for 1988 . However, there is some variation in hours per month (corresponding to 8, 8.5, or 9 hours per day, for example), which smooths out the mass at the minimum of monthly earnings.

${ }^{21}$ As discussed in the Appendix, the slope of the relationship in Figure 2 between average wages at ages 35-42 and pre-conscription wages (which is 0.53 ) is nearly identical to the slope predicted by the simple model we use to obtain an estimate of the loading factors $\psi_{t}$ at different ages, providing a validation test for that model.

${ }^{22}$ Recall that conscripts are men who worked in 1987 and were on leave in 1988 and 1989, or worked in 1988 and were on leave in 1989 . We only have a 1988 wage observation for those in the latter category.
} 
1992 and 2000 (ages 27-33) and a relatively steady 3-point gap between 2002 and 2009 (ages 34 to 42 ).

Figures $3 \mathrm{~b}$ and $3 \mathrm{c}$ present the corresponding wage profiles for two subgroups: "low education" men with no more than 4 years of schooling at age 20/21 (23\% of whom are veterans); and "high education" group with 6 or more years of schooling (31\% of whom are veterans). For both education groups the pre-conscription wage profiles of veterans and non-veterans are very similar, with less than a $1 \%$ wage gap between them in any year. In the immediate post-service years the low-educated veterans have very similar wages to their non-veteran counterparts. By 2002, however, the veterans have systematically higher wages, with a gap of about $5 \%$ at the end of our sample period. Among the high-educated group veterans and non-veterans have very similar wages throughout the period from 1991 to 2000 (ages 23-33) and only very slightly higher average wages in the last years of our sample.

A potential issue with the wage comparisons in Figures 3a-3c is that the fractions of conscripts and non-conscripts who are observed with a wage may be different at a given age, leading to potential selectivity biases in the observed wage gaps. Figures 4a-4c plot the age profiles of the probability of appearing as a wage-earner in the QP. All three graphs show that the conscript group had somewhat higher employment rates than the non-conscripts in the two earliest years (1986 and 1987). The situation is reversed in 1988 and 1989, however, since by construction the men we classify as non-veterans were working in 1988 and 1989, whereas the men we classify as veterans were all on leave in 1989 (20\% were also on leave in 1988).

In the years immediately following their military service the conscripts as a whole have slightly lower employment rates than the non-conscripts (e.g., a gap of -3.6 percentage points in 1991, and a gap of -1.9 points in 1997). After 2002 the gaps are uniformly small (under 1 percentage point in magnitude). For the less-educated subgroup (Figure $4 \mathrm{~b}$ ) the employment gaps vary a little more over time, but are never larger than 3 percentage points in absolute value. For the more-educated subgroup (Figure 4c) the employment gaps are a little larger between 1991 and 1999, but are very small after 2001 . These patterns suggest that wage comparisons between conscripts and non-conscripts under the age of 30 have to be interpreted cautiously, since the conscript group has a somewhat lower employment rate in this age range, potentially inducing a selectivity bias. After age 35, however, there is less concern about selectivity.

In the Appendix we present an extended series of graphical comparisons that sup- 
plement the findings in Figures 3 and 4. First, we show the age profiles of wages and employment for women born in 1967 who meet the same criteria as our conscript and non-conscript groups. Female "conscripts" are presumably women who took maternity leave at ages 21 and/or 22, while "non-conscripts" are women who worked continuously at those ages. Consistent with other evidence on the costs of child-bearing (e.g., Light and Ureta, 1995), we find that women who take leave at a young age tend to have lower wages later in their careers than those who did not. The gap is particularly pronounced for higher-educated women, as might be expected if career interruptions have a higher cost for them. Employment rates of women who took leave in their early 20's are also lower than the rates for those who did not. The negative impacts of leave-taking for young women contrast with the generally positive wage effects (and 0 employment effects) for men, and confirms that there is not a simple mechanical explanation for the male effects.

We also present graphs showing the wage and employment outcomes for all four groups of early labor market entrants defined in Table 2 (i.e., our two main groups of conscripts and non-conscripts, plus men who were missing from the QP at age 22, and the residual group). Generally speaking, the wages of all four groups are fairly similar, though the residual group tends to have slightly lower wages than the other three. The employment rates of the groups vary more - in particular, as noted in the discussion of Table 2, the group who were not in the QP in 1989 have substantially lower employment rates at all ages than those who were recorded as unpaid leave in that year. We interpret this as supporting the logic of our classification scheme, which treats being "on leave" as fundamentally different from being absent altogether from the survey.

\section{Regression Models}

In this section we present our main estimation results for models of the effect of conscription on post-conscription earnings. We begin in Table 3 with results for the wage on the job held immediately prior to conscription (i.e., the wage $w_{0}$, measured at age 20 or 21 ). The model in column (1) is fit to our entire sample of conscripts and non-conscripts, and shows a small positive wage gap between conscripts and non-conscripts, consistent with the results in Figure 3a. The model in column (2) adds a set of dummies for education (measured at age 20/21). Since conscripts are somewhat better educated than

non-conscripts, and better-educated workers tend to earn more, the addition of these controls leads to a small negative estimate of the pre-conscription wage gap. Columns 3- 
6 show parallel sets of models for men with lower education at age $20 / 21$, and those with higher education. In both subgroups conscripts have lower wages than non-conscripts, though the gaps after controlling for education are small and statistically insignificant. ${ }^{23}$

Based on the evidence in Figures 3a-3c and the regression results in Table 3, we conclude that the pre-conscription wages for conscripts and non-conscripts who were working full time at age 20/21 are very similar. As discussed above, in this situation alternative values for the parameter $\psi_{t}$ in equation (5) or (6) will yield similar estimates of the effect of conscription on subsequent wages, though with larger values of $\psi_{t}$ the adjustment for the pre-conscription wage gap can be 2-3 times as large as the initial wage gap. Our approach is to summarize the results using a range of values of $\psi_{t}$ from 0 to our estimate of $\bar{\psi}=2.62$. Of particular interest is the case of $\psi_{t}=1$, which corresponds to a conventional difference-in-differences estimate. Another useful benchmark is the value of $\psi_{t}$ that arises from an OLS regression of $w_{t}$ on the pre-conscription wage $w_{0}$ (controlling for initial schooling). ${ }^{24}$

Table 4 summarizes the estimated veteran effects associated with the various choices for the quasi-differencing factor $\psi_{t}$. Given the relative stability of the wage gaps at different ages in Figures 3a-3c, we simplify the presentation by focusing on pooled models that combine wages in two sub-periods: the years from 1991 to 2000, which represents the first decade after completion of military service by the conscripts; and the years from 2002 to 2009, which represents the "mid-career" period for men born in 1967. More detailed year-by-year results are reported in the Appendix.

The first panel of Table 4 shows results for the overall sample. For the 1991-2000 period, the estimation results show a small effect that is within a standard error of 0 for all values of the quasi-differencing factor. For the later period the average effect is $2.1 \%$ with no control for pre-enlistment wages, $2.1 \%$ when the pre-enlistment wage is entered freely in the regression model (its estimated coefficient is 0.36 ), $2.0 \%$ when wages in all periods are differenced from the pre-enlistment wage, and $1.9 \%$ when we quasi-difference using a factor of 2.62. The stability of the estimates across different

\footnotetext{
${ }^{23}$ We have also fit models that include a dummy indicating whether the pre-conscription wage is measured in 1988 (versus 1987). For the overall sample this variable has a coefficient of 0.044 suggesting that wages were about $4 \%$ higher if measured in 1988 . The addition of this variable leads to an estimated conscription dummy of $0.47 \%$ (standard error $=0.71$ ). In the robustness section below we discuss results where we inflate pre-conscription wages by $4.4 \%$ if measured in 1987.

${ }^{24}$ Assuming that the pre-conscription wages of veterans and non-veterans are equal, a model with pre-conscription wages as a control variable will yield the most efficient estimate of the veteran effect (i.e., the estimate with the smallest standard error).
} 
values of the differencing factor is illustrated in Figure 5a, where we plot the estimated enlistment effect for 2002-2009 against various values for the quasi-differencing factor, ranging from 0 to 3 , as well as the pointwise $95 \%$ confidence intervals. Though the estimates from higher values of the quasi-differencing factor are relatively imprecise, the point estimates are essentially invariant to the value of the quasi-differencing factor, reflecting the very small gap in pre-conscription wages between conscripts and nonconscripts who are observed with at least one wage in the 2002-2009 period.

The middle and lower panels of Table 4 report a parallel series of models estimated for the subsets of men with lower or higher levels of education just prior to enlistment. As suggested by the wage profiles in Figure 3b, the average veteran effect for less educated men in the first decade after service is very close to zero. In the 2002-2009 period, however, the effect is around $4 \%$, and is statistically significant at conventional levels for the models with $\psi_{t} \leq 1$. For the more educated subgroup the wage effects of conscription are never large or significant, and the estimates for 2002-2009 are very close to 0 . The patterns of the estimated veteran effects on mid-career wages for different values of the quasi-differencing factor are summarized in Figures $5 \mathrm{~b}$ and $5 \mathrm{c}$. As in the overall sample, the estimated wage effects are quite robust, reflecting the fact that enlistment status is nearly uncorrelated with pre-enlistment wages.

Assuming that pre-conscription wages are orthogonal to enlistment status, the decision of which particular value of $\psi_{t}$ to use in the estimation of post-conscription treatment effects can be based on efficiency considerations. Under orthogonality between ability and enlistment status, a simple OLS regression on schooling, initial wages, and enlistment status provides the least-variance estimates. We therefore focus on this specification - i.e., the estimates presented in column 3 of Table 4 - as the basis for our "preferred" estimates.

\section{Robustness Checks}

Our analysis so far has focused on comparisons between two subgroups of men who we can easily classify as either conscripts or non-conscripts. In this section we consider the robustness of our conclusions to changes in the way that we define these two groups. The results are summarized in Table 5, where we show estimates of the pooled enlistment

effect for ages 35-42 from specifications with different quasi-differencing factors, using alternative definitions of the conscripted and non-conscripted groups. We show results for the overall sample in panel (a); results for the low-education subgroup in panel (b); 
and results for the high-education subgroup in panel (c).

Focusing first on the results in panel (a), the first row shows the results from our "baseline" sample definition (these are taken from the top panel of Table 4). In row 2 we relax our definition of "early entrants" - which is based on full time work at age 20 or 21 in our baseline samples - to include part time workers. ${ }^{25}$ This expands the sample by about $15 \%$, and leads to estimates that are slightly higher than our baseline estimates across the range of values for $\psi_{t}$.

Our basic conscript definition includes two groups of men: those who were working full time in March 1987 and on leave in the next two years; and those who were working full time in March 1988 and on leave in the next year. Arguably, the requirement that the first group be on leave in both 1988 and 1989 may be too strict, since some men may have been inducted in the early months of 1988 and served only a year in the military. In row 3 we expand the definition of conscripts to include men who were working full time in March 1987, on leave the next year, and observed in any status in March 1989. This increases the conscript group by about $40 \%$, and has little impact on the estimates with no control for the pre-conscription wage (columns 1-2) or with the pre-conscription wage included as a regressor (columns 3-4). However, in the differenced specification (columns 5-6) the alternative sample yields a somewhat larger estimate than the baseline sample (3.8\% versus $2.0 \%)$, and in the quasi-differenced specification with $\psi_{t}=2.62$, it yields a relatively large positive estimate $(6.6 \%)$. This is attributable to the fact that the pre-conscription wages of the added conscripts (i.e., those who were working full time in March 1987, on leave in March 1988, and not on leave in March 1989) are slightly lower than those of other groups, and when $2.62 w_{0}$ is subtracted from wages observed at later ages they appear to have a significant wage advantage. We interpret the large point estimate arising from the quasi-differenced model when this group is included as an "upper bound" on the likely effect of conscription on the overall sample of men.

In row 4 we consider narrowing the conscript group from our baseline by imposing the extra requirement that men who were working full time in March 1988 and on leave in March 1989 also were working full time in March 1987. This reduces the size of the conscript group by about $25 \%$ and leads to estimates that are slightly larger in the specifications that ignore the initial wage or include it as a control, but slightly smaller

\footnotetext{
${ }^{25}$ Thus, non-conscripts are defined as men who were observed working (with a valid wage) in 1988 and 1989, and conscripts are defined as men who either were working in March 1987 and on leave in March 1988 and 1989, or working in March 1988 and on leave in March 1989.
} 
in the specifications with $\psi_{t}=1$ or $\psi_{t}=2.62$.

Finally, in row 5 we address a potential non-comparability between the way we measure pre-conscription wages for men who served in the military and men who did not. Recall that for non-veterans we use the wage in 1988 as our measure of $w_{0}$. For the $80 \%$ of conscripts who were working in 1988 and on leave in 1989 we do the same. But for the other 20\%, who were working in 1987 and on leave in 1988 and 1989, we use the wage in 1987 as the measure of $w_{0}$. This may lead to some understatement of pre-conscription wage for the veterans. As a check, we inflated 1987 wages for the relevant subgroup by $4.4 \%$ (the estimate that comes out of a model for pre-conscription wages that controls for schooling and whether the wage was measured in 1987 or 1988). Applying the adjustment leads to a slightly smaller estimate of the effect of veteran status on wages at mid-career across the various specifications.

Inspection the results in panels (b) and (c) shows that departures from our baseline sample definition lead to estimated veteran effects for men with lower or higher education that are generally quite similar to our baseline estimates. In particular, for the low education group the range of estimated veteran effects is from $2.2 \%$ to $10 \%$, with most of the estimates clustered in the range from $4 \%$ to $6 \%$. For the high-education group, by comparison, the estimates range from $-2.2 \%$ to $3.7 \%$, with most of the estimates clustered around 0 .

Overall we interpret the robustness checks as providing general support for the conclusions derived from our baseline sample. A caveat is that our use of pre-enlistment wages to control for unobserved ability differences between conscripts and non-conscripts is relatively sensitive to the size of the pre-enlistment wage gap - particularly when this gap is multiplied by a large value of $\psi_{t}$. Empirically the pre-conscription wage gaps are all relatively small. If one takes these gaps as indicative that the true ability gap between conscripts and non-conscripts is 0 , then the most reliable estimates of the veteran effect emerge from models that use the pre-conscription wage as a control variable. These models yield quite stable and relatively precise estimates of the veteran effect, with a value of $4-5 \%$ for low-education conscripts and approximately 0 for high-education conscripts.

\section{Mechanisms}

The estimates in Table 4 show a significant but modestly-sized effect of conscription on the mid-career wages of low-educated men, coupled with a zero effect on higher-educated 
men. In this section we briefly discuss some of the possible channels for the conscription effect, including education, labor market experience, and location.

The models in Table 6 explore the potential role of education. Specifically, these models test whether military service had any effect on the rate of acquisition of additional schooling between age 20 and 40. The sample includes conscripts and non-conscripts who are observed working at least once between 2002 and 2009: we measure the change in education from age 20/21 to the last available year in this period. ${ }^{26}$ On average the early labor market entrants in our sample gained 0.77 years of education over their twenties and thirties. As shown in column (1) of Table 5 the average gain is only slightly larger for the conscripts $(+0.07$ years, standard error $=0.05)$. As might be expected, however, the gains differ for men with differing levels of initial education, and since the conscripted group under-represents both very low educated men, and those with the most education, it is important to control for initial education in measuring the effect of conscription. Adding these controls (column 2) leads to small but significantly positive enlistment effect $(+0.14$ years, $\mathrm{t}=2.64)$.

The remaining columns of Table 6 show parallel models for the subgroups with less than 6 years of initial schooling and 6 or more years of initial education. In the loweducation subgroup enlistees gain about $\frac{1}{4}$ of a year more schooling than non-enlistees, while in the high-education subgroup there is no effect of enlistment. Assuming a return to education of about $8 \%$ in the Portuguese market in the 2000's (which is the range that arises from a standard human capital earnings function) this extra schooling would generate roughly 2 percentage points higher wages for low-education veterans: enough to account for about half of the wage advantage we estimate in Table $4 \mathrm{~b}$ for these men.

We conducted a similar analysis of cumulative labor market experience. As might be expected given the very similar probabilities of employment of conscripts and nonconscripts documented in Figures 4a-4c, however, cumulative labor market experience of veterans and non-veterans increases at nearly the same rate for the two groups. Thus, experience effects appear to play almost no role in the emergence of a wage gap for veterans by mid-career.

Another possible channel for the wage effect of military service is through geographic location. About one-third of the Portuguese labor force works in the Lisbon area, and wages are on average about $16 \%$ higher there. We conjectured that the experience of

\footnotetext{
${ }^{26}$ Among men observed at least once in 2002-2009, 75\% are last observed in 2009 and $90 \%$ are observed in 2006 or later.
} 
serving in the military could have some effect on the willingness of men from small towns and rural areas to migrate to Lisbon. Empirically, however, there is no evidence of differential migration behavior, so this channel cannot explain the veteran effect.

We also conducted an informal "accounting exercise" in which we compared the measured veteran effect from a model with no additional controls, and models with controls for industry and occupation. This exercise is similar to the "Oaxaca decomposition" technique that is widely used to help understand gender and race-related wage gaps (see Fortin, Lemieux, Firpo, 2011 for a recent discussion). We find that differences in industry account for very little of the measured veteran effect for low-education men, while differences in occupation can account for about one-half of the effect. The relatively higher fraction of veterans in higher-wage occupations could be due in part to their relative gains in schooling, and also other forms of vocational training that are not recorded in the QP data.

\section{Inter-cohort Comparisons}

A limitation of the estimates presented in Tables 4 and 5 is they pertain to a relatively narrow subset of men who were working by age 20 or 21 . As a check on the potential generalizeability of these results to the broader population, this section briefly discusses an alternative evaluation design that uses inter-cohort comparisons in the conscription rate.

As noted in Table 1, the fraction of men who were conscripted varies by cohort, with a range from 30 to 45 percent among cohorts who served for up to two years in the military. Assuming that conscription rates are uncorrelated with other factors that influence the long-run earnings of men in a given cohort, and that conscription has a homogeneous effect, one could estimate the effect from a simple regression of mean wages for the men in a cohort (observed at some range of ages) on the fraction of the cohort who were conscripted. A problem for this approach is that different cohorts are never observed at the same age in the same year. Thus, some assumptions are needed to separately identify cohort, age, and time effects. We assume that the effects of age on wages can be captured by a (time-varying) smooth polynomial, and fit models for log wages that include year effects, a cubic in age (fully interacted with year) and unrestricted cohort effects:

$$
w_{i c t}=a_{0 t}+a_{1 t}(t-c)+a_{2 t}(t-c)^{2}+a_{3 t}(t-c)^{3}+\omega_{c}+e_{i c t},
$$


where $w_{i c t}$ is the $\log$ wage of individual $i$ born in year $c$ and observed in year $t$, $\left\{a_{0 t}, a_{1 t}, a_{2 t}, a_{3 t}\right\}$ are the coefficients of time-period-specific cubics in age, and $\omega_{c}$ are cohort fixed effects. We then relate the cohort effects to the fraction of the cohort who served in the military $\left(V_{c}\right)$ :

$$
\omega_{c}=\mu+\theta V_{c}+e_{c}
$$

We use wage data for the period from 2002-2009 for men born from 1955 to 1975, but fit the second stage model to the narrower set of cohorts born from 1959 to 1969. These cohorts served in the military from 1980 to 1990 under relatively stable conditions, and were all subject to a maximum limit of two years of service. The advantage of fitting the first step model to the broader set of cohorts is that it provides a wider age range over which to estimate the age polynomials. To get correct standard errors for the estimate of $\theta$ we actually fit a one-step model that combines equations (6) and (7) and clusters the standard errors by birth year. ${ }^{27}$

Figure 6 shows the estimated cohort dummies obtained from equation (6), along with the fraction of the cohort who served in the military. Inspection of the graph suggests that cohort average wages and the fraction of conscripts are not very strongly related, though the overall correlation is weakly positive. The one-step estimate of $\theta$ is $4.5 \%$, with a standard error of $5 \%$, providing a relatively wide $95 \%$ confidence interval for the cohort-wide conscription effect that ranges from $-5.5 \%$ to $+9.5 \%$. Our conclusion is that the aggregate evidence is consistent with our main estimates for men who were working prior to the age of conscription. Moreover, we can definitely rule out large negative effects of mandatory military service for the cohort as a whole.

\section{Summary and Conclusions}

In this paper we use detailed administrative data covering the entire private sector of the Portuguese economy to study the long-term effects of peace-time military service on men born in 1967 who were working prior to age 21, when they were subject to mandatory conscription. We present a series of difference-in-differences estimators that use preconscription wages to control for unobserved ability differences between veterans and non-veterans. Wages of veterans and non-veterans track each other very closely in the years before conscription, and mean wages of the two groups at the job held just before

\footnotetext{
${ }^{27}$ We fit a version of equation (6) that includes unrestricted cohort dummies for the oldest cohorts (born 1955-58) and youngest cohorts (born 1970-75) and the fraction of conscripts for the cohorts born from 1959 to 1969.
} 
the determination of conscription status are very similar (conditional on schooling), suggesting that the two groups have very similar unobserved abilities. As a result, our estimates of the long-run wage impacts of conscription are robust to alternative assumptions about the evolution of ability-related wage differences over the career.

We find a small positive, but statistically insignificant impact of military service on wages at mid-career (ages 35-42). This is similar to recent findings on the effects of peacetime conscription in Britain (Grenet et al., 2011) and West Germany (Bauer et al., 2009), and also to recent estimates of the effect of military service on Vietnam era draftees at age 40 (Angrist, Chen and Song, 2011). The small average effect, however, represents an average of a larger positive effect for men with only a primary education (about one-half of the early labor market entrants in the cohort) and a zero effect for better-educated men. The positive impact on the low-educated subgroup is partially explained by the fact that enlistees with initially low education acquire more education than non-enlistees. They also work in somewhat better-paying industries and occupations. We conjecture that the higher schooling and occupational outcomes may be due to basic skills and occupational training received in the military, though we have no direct data on the extent of this training. Low-educated veterans have, if anything, slightly higher long-run probabilities of private sector employment than non-veterans, providing no indication of the elevated criminal propensities found by Galiani et al. (2011) for Argentine veterans.

Several features of the institutional setting may have contributed to the positive impact of service for less-educated men in our sample. First, these men had at most 4 years of schooling when they entered the military. A year of basic skills training could have a potentially important impact on such men - allowing some to achieve literacy, for example. Second, Portuguese law required firms to rehire draftees at the completion of their service. This may have eased the transition back to civilian life for the conscripts in our analysis, who all held full time jobs just before entering the military. Third, it is important to emphasize that the military service we study occurred during peacetime. Nevertheless, our findings are consistent with a stream of U.S. findings, including de Tray (1982), Berger and Hirsch (1983), Angrist (1998), and Hirsch and Mehay (2003) which suggest that military service can have a positive wage impact for relatively disadvantaged men, perhaps comparable in magnitude to the impact of other labor market training programs. 


\section{References}

Albrecht, James W., Per-Anders Edin, Marianne Sundstrom and Susan B. Vroman (1999). Career Interruptions and Subsequent Earnings: A Reexamination Using Swedish Data. Journal of Human Resources, 34(2), 294-311.

Altonji, Joseph G. and Charles R. Pierret (2001). Employer Learning and Statistical Discrimination. Quarterly Journal of Economics, 116(1), 313-350.

Angrist, Joshua D. (1990). Lifetime Earnings and the Vietnam Era Draft Lottery: Evidence from Social Security Administrative Records. American Economic Review, 80(3), 313-36.

Angrist, Joshua D. (1998). Estimating the Labor Market Impact of Voluntary Military Service Using Social Security Data. Econometrica, 66(2), 249-288.

Angrist, Joshua D., and Stacey H. Chen (2011). Schooling and the Vietnam-Era GI Bill: Evidence from the Draft Lottery. American Economic Journal: Applied Economics, 3, 96-118.

Angrist, Joshua D., Stacey H. Chen, and Jae Song (2011). Long Term Consequences of Vietnam-Era Conscription: New Estimates Using Social Security Data. American Economic Review, 2, 334-338.

Arcidiacono, Peter, Patrick Bayer, and Aurel Hizmo (2008). Beyong Signaling and Human Capital: Education and the Revelation of Ability. NBER Working Paper 13951

Ashenfelter, Orley. (1978). Estimating the Effects of Training Programs on Earnings. Review of Economics and Statistics, 60, 47-57.

Ashenfelter, Orley and David Card (1985) Using the Longitudinal Structure of Earnings to Estimate the Effect of Training Programs. Review of Economics and Statistics, 67 (4), 648-660..

Autor, David H., Mark G. Duggan and David S. Lyle (2011). Battle Scars: The Puzzling Decline in Employment and Rise in Disability Receipt among Vietnam Era Veterans. American Economic Review, 2, 339-344.

Baganha, Maria Joannis and José Carlos Marques (2001). "Population." In Nuno Valério (coord.), Portuguese Historical Statistics. Lisbon: National Statistical Office, p. 66.

Bauer, Thomas K., Stefan Bender, Alfredo R. Paloyo, and Christoph M. Schmidt (2009). Evaluating the Labor Market Effects of Compulsory Military Service. IZA Discussion Paper No. 4535.

Bedard, Kelly and Olivier Deschênes (2006). The Long-term Impact of Military Service on Health: Evidence from World War II and Korean War Veterans. American Economic Review, 96(1), 176-194.

Berger, Mark C. and Barry T. Hirsch (1983). The Civilian Earnings Experience of Vietnam-Era Veterans. Journal of Human Resources, 18(4), 455-479.

Braguinsky, Serguey, Lee G. Branstetter, and Andre Regateiro (2011). The Incredible Shrinking Portuguese Firm. NBER Working Paper No. 17265.

Cardoso, Ana Rute (1998). Earnings Inequality in Portugal: High and Rising? Review of Income and Wealth, 44(3), 325-343. 
Cardoso, Ana Rute and Pedro Portugal (2005). Contractual Wages and the Wage Cushion under Different Bargaining Settings. Journal of Labor Economics, 23(4), 875-902.

Carrington, William J. and Pedro J. F. de Lima (1996). The Impact of 1970s Repatriates from Africa on the Portuguese Labor Market. Industrial and Labor Relations Review, 49(2), 330-347.

Centeno, Mário and Alvaro A. Novo (2009). When Supply Meets Demand: Wage Inequality in Portugal. IZA Discussion Paper No. 4592.

Chamberlain, Gary (1982). Multivariate Regression Models for Panel Data. Journal of Econometrics, 18, 5-46.

Cipollone, Piero, and Alfonso Rosolia (2007). Social Interactions in High School: Lessons from an Earthquake. American Economic Review, 97(3), 948-965.

de Tray, Dennis (1982). Veteran Status as a Screening Device. American Economic Review, 72(1), 133-142.

Dokbin, Carlos and Reza Shabani (2009). The Health Effects of Military Service: Evidence from the Vietnam Draft. Economic Inquiry, 47(1), 69-80.

Domingues, João Marco (1998). A Objecção de Consciência. Janus, Anuário, Suplemento Especial Forças Armadas Portuguesas.

European Foundation for the Improvement of Living and Working Conditions (1997). Preventing Absenteeism at the Workplace: Research Summary. Luxembourg: Office for Official Publications of the European Communities.

Farber, Henry S. and Robert Gibbons (1996). Learning and Wage Dynamics. Quarterly Journal of Economics, 111: 1007-1047.

Fortin, Nicole, Thomas Lemieux, and Sergio Firpo (2011). Decomposition Methods in Economics. In Orley Ashenfelter and David Card (eds.), Handbook of Labor Economics, Volume 4, Part A. Amsterdam: Elsevier, p. 1-102.

Galiani, Sebastian, Martín A. Rossi, and Ernesto Schargrodsky (2011). Conscription and Crime: Evidence from the Argentine Draft Lottery. American Economic Journal: Applied Economics, 3, 119-136.

Graham, Lawrence S. (1979). The Military in Politics. In Lawrence S. Graham and Harry M. Makler (eds.), Contemporary Portugal: The Revolution and Its Antecedents. Austin, TX: University of Texas Press.

Grenet, Julien, Robert A. Hart, and J. Elizabeth Roberts (2011). Above and Beyond the Call: Long-term Real Earnings Effects of British Male Military Conscription in the Post-War Years. Labour Economics, 18(2), 194-204.

Haider, Steven and Gary Solon (2006). Life-cycle Variation in the Association between Current and Lifetime Earnings. American Economic Review, 96(4), 1308-1320.

Hirsch, Barry T. and Stephen L. Mehay (2003). Evaluating the Labor Market Performance of Veterans Using a Matched Comparison Group Design. Journal of Human Resources, 38(3), 673-700.

Imbens, Guido and Wilbert van der Klaauw (1995). Evaluating the Cost of Conscription in The Netherlands. Journal of Business and Economic Statistics, 13, 207-215. 
Keller, Katarina, Panu Poutvaara, and Andreas Wagener (2009). Does Military Draft Discourage Enrollment in Higher Education? Evidence from OECD Countries. IZA Discussion Paper No. 4399.

Kunze, Astrid (2002). The Timing of Careers and Human Capital Depreciation. IZA Discussion Paper No. 509.

Lange, Fabian (2007). The Speed of Employer Learning. Journal of Labor Economics, $25(1), 1-35$.

Lemieux, Thomas (1998). Estimating the Effects of Unions on Wage Inequality in a Panel Data Model with Comparative Advantage and Nonrandom Selection. Journal of Labor Economics, 16(2), 261-291.

Light, Audrey and Manuelita Ureta (1995). Early-Career Work Experience and Gender Wage Differentials. Journal of Labor Economics, 13(1), 121-154.

Maurin, Eric and Teodora Xenogiani (2007). Demand for Education and Labor Market Outcomes. Lessons from the Abolition of Compulsory Conscription in France. Journal of Human Resources, 42 (4), 795-819.

Oi, Walter Y. (1967). The Economic Cost of the Draft. American Economic Review, $57(2), 39-62$.

Paloyo, Alfredo R. (2010). Compulsory Military Service in Germany Revisited. RUHR Economic Paper No. 206.

Pordata (2011). Emprego. www.pordata.pt, retrieved June 6th.

Portugal. Estado Maior do Exército (2000). Evolução das Incorporações no Exército.

Portugal. Instituto Nacional de Estatística (2011). Greves. www.ine.pt, retrieved July 6 th.

Portugal. Ministério do Trabalho e da Segurança Social (1986 to 2009). Quadros de Pessoal. Data in magnetic media.

Rebelo, Glória (2003). Trabalho Independente em Portugal: Empreendimento ou Risco? Working Paper No. 2003/32, Dinamia-Centro de Estudos sobre a Mudança Socioeconómica.

Schoenberg, Uta (2007). Testing for Asymmetric Employer Learning. Journal of Labor Economics, 25(4), 651-691.

Tarrter, Jean R. (1993). Chapter 5: National Security. In Country Studies: Portugal. Washington DC: Library of Congress Federal Research Division. Downloaded from http://lcweb2.loc.gov/frd/cs/pttoc.html. 
Table 1: Cohort Size, Age of Conscription, Conscription Rate, ANd MAXIMUM Length Of Service

\begin{tabular}{|c|c|c|c|c|c|}
\hline $\begin{array}{l}\text { Year of } \\
\text { Birth }\end{array}$ & $\begin{array}{c}\text { Number } \\
\text { of Men in Cohort } \\
(1000 \text { 's }) \\
\text { (1) }\end{array}$ & $\begin{array}{l}\text { Age of } \\
\text { Conscription } \\
\text { for Cohort } \\
\text { (2) }\end{array}$ & $\begin{array}{l}\text { Number of Men } \\
\text { Conscripted } \\
\text { (1000's) } \\
\text { (3) }\end{array}$ & $\begin{array}{c}\text { Percent of Men } \\
\text { Conscripted } \\
\text { (4) }\end{array}$ & $\begin{array}{l}\text { Maximum } \\
\text { Length of } \\
\text { Service (mo.) } \\
\text { (5) }\end{array}$ \\
\hline 1959 & 109.7 & 21 & 35.5 & 32.4 & 24 \\
\hline 1960 & 110.5 & 21 & 33.1 & 30.0 & 24 \\
\hline 1961 & 111.9 & 21 & 30.7 & 27.5 & 24 \\
\hline 1962 & 113.8 & 21 & 34.2 & 30.0 & 24 \\
\hline 1963 & 109.5 & 21 & 39.1 & 35.7 & 24 \\
\hline 1964 & 112.4 & 21 & 38.3 & 34.1 & 24 \\
\hline 1965 & 108.6 & 21 & 36.4 & 33.6 & 24 \\
\hline 1966 & 107.2 & 21 & 36.8 & 34.3 & 24 \\
\hline 1967 & 103.9 & 21 & 40.9 & 39.3 & 24 \\
\hline 1968 & 101.1 & 21 & 39.3 & 38.8 & 24 \\
\hline 1969 & 98.1 & 21 & 34.0 & 34.7 & 24 \\
\hline 1970 & 89.2 & 21 & 41.9 & 46.9 & 8 \\
\hline 1971 & 97.3 & 21 & 37.1 & 38.1 & 8 \\
\hline 1972 & 90.3 & 21 & 41.9 & 23.4 & 4 \\
\hline 1973 & 88.7 & 20 & & & 4 \\
\hline 1974 & 88.1 & 20 & 40.0 & 45.4 & 4 \\
\hline 1975 & 93.1 & 20 & 43.7 & 46.9 & 4 \\
\hline 1976 & 96.6 & 20 & 36.6 & 37.9 & 4 \\
\hline 1977 & 94.0 & 20 & 29.4 & 31.3 & 4 \\
\hline 1978 & 87.1 & 20 & 29.2 & 33.6 & 4 \\
\hline 1979 & 82.7 & 20 & 28.9 & 35.0 & 4 \\
\hline
\end{tabular}

Note: Column (1) is number of men born in indicated year. Column (2) is legal age of conscription. Column (3) is number of men conscripted into the army in the year the cohort turned 21 (born 1972 or earlier) or 20 (born 1973 or later). Number conscripted excludes a small number of men conscripted into the airforce and navy. Men born in 1972 and 1973 were both conscripted in 1993, and entry in column (3) is total for both cohorts. Column (4) represents the ratio of column (3) to column (1): for the cohorts born in 1972 and 1973 we assume equal conscription rates. Column (5) is the maximum length of service. See Data Appendix for sources. 
Table 2: Summary Statistics on Sub-Groups of MALE COHORT BORN 1967

\begin{tabular}{|c|c|c|c|c|c|c|c|c|}
\hline & \multirow{3}{*}{$\begin{array}{c}\text { Complete } \\
\text { Cohort }\end{array}$} & \multicolumn{6}{|c|}{ Early Entrants (Working Full-Time in 1987 or 1988) } & \multirow{3}{*}{$\begin{array}{c}\text { Not } \\
\text { Early } \\
\text { Entrants }\end{array}$} \\
\hline & & \multirow[b]{2}{*}{ Total } & \multicolumn{3}{|c|}{ Conscripted } & \multirow{3}{*}{$\frac{\text { Missing }}{(6)}$} & \multirow{3}{*}{$\frac{\text { Residual }}{(7)}$} & \\
\hline & & & Yes/No & Yes & No & & & \\
\hline & $(1)$ & $(2)$ & (3) & (4) & (5) & & & $(8)$ \\
\hline Number of observations & 86,909 & 18,517 & 6,749 & 1,838 & 4,911 & 9,502 & 2,266 & 68,392 \\
\hline \multicolumn{9}{|l|}{ Pre-conscription: } \\
\hline \multicolumn{9}{|l|}{ Share with observed wage } \\
\hline 1986 & 14.1 & 46.6 & 51.4 & 62.1 & 47.4 & 39.9 & 61.0 & 5.3 \\
\hline 1987 & 16.5 & 72.3 & 66.4 & 77.5 & 62.3 & 71.5 & 93.2 & 1.4 \\
\hline 1988 & 15.5 & 68.0 & 95.0 & 81.5 & 100.0 & 58.9 & 25.7 & 1.2 \\
\hline 1989 & 13.2 & 36.7 & 72.8 & 0.0 & 100.0 & 0.0 & 82.9 & 6.8 \\
\hline \multicolumn{9}{|l|}{ Share on leave of absence } \\
\hline 1986 & 0.5 & 1.1 & 1.2 & 1.0 & 1.3 & 1.0 & 1.4 & 0.4 \\
\hline 1987 & 0.6 & 0.9 & 1.5 & 1.4 & 1.6 & 0.6 & 0.2 & 0.5 \\
\hline 1988 & 2.1 & 6.0 & 5.0 & 18.5 & 0.0 & 3.3 & 19.8 & 1.1 \\
\hline 1989 & 3.4 & 11.8 & 27.2 & 100.0 & 0.0 & 0.0 & 15.0 & 1.2 \\
\hline \multicolumn{9}{|l|}{ (Log) real hourly wage } \\
\hline 1986 & 0.60 & 0.61 & 0.62 & 0.63 & 0.61 & 0.60 & 0.62 & 0.58 \\
\hline 1987 & 0.78 & 0.78 & 0.79 & 0.80 & 0.78 & 0.77 & 0.78 & 0.78 \\
\hline 1988 & 0.84 & 0.84 & 0.85 & 0.86 & 0.85 & 0.83 & 0.88 & 0.83 \\
\hline 1989 & 0.91 & 0.92 & 0.92 & & 0.92 & & 0.93 & 0.90 \\
\hline \multicolumn{9}{|l|}{ Schooling: } \\
\hline Share $<=4$ years at entry & 40.8 & 53.7 & 53.2 & 46.4 & 55.8 & 53.9 & 54.5 & 37.3 \\
\hline Av. at entry into labor market & 6.9 & 5.3 & 5.3 & 5.5 & 5.3 & 5.3 & 5.2 & 7.3 \\
\hline Av. in 2002 & 7.1 & 5.8 & 5.8 & 6.0 & 5.8 & 5.8 & 5.7 & 7.5 \\
\hline \multicolumn{9}{|l|}{ Post-conscription: } \\
\hline Share with wage obs, 2002-2009 & 60.9 & 62.2 & 72.6 & 72.4 & 72.7 & 52.4 & 72.0 & 60.6 \\
\hline (Log) real hourly wage, 2002-09 & 1.66 & 1.54 & 1.55 & 1.57 & 1.54 & 1.55 & 1.52 & 1.71 \\
\hline
\end{tabular}

Note: Early entrants are defined as men who were observed working full time in either 1987 or 1988 . Conscripted men include men who were working full time in 1987, and were on leave of absence (listed on the roster of employees with missing values for wages and hours) in 1988 and 1989, plus men who were working full time in 1988 and on leave in 1989. Non-conscripted men are those who were working full time in 1988 and 1989. "Missing" group in column 6 are those who were working full time in 1987 or 1988 and are not present in the QP in 1989. "Residual" group in column 7 are all men who were working full time in 1987 or 1988 and are not included as conscripts, non-conscripts, or missing. Share with wage observation(s), 2002-2009 refers to the fraction of the group indicated in the column heading who were observed as wage earners in the QP at least once between 2002 and 2009. 
Table 3: Estimated Effect of Conscription on Log of Pre-Conscription WAges

\begin{tabular}{|c|c|c|c|c|c|c|}
\hline & \multicolumn{2}{|c|}{ All } & \multicolumn{2}{|c|}{ Low-Education } & \multicolumn{2}{|c|}{ High-Education } \\
\hline & (1) & (2) & (3) & (4) & (5) & (6) \\
\hline \multirow[t]{2}{*}{ Conscription Dummy (coefficient×100) } & 0.17 & -0.36 & -0.28 & -0.28 & -1.02 & -0.43 \\
\hline & $(0.68)$ & $(0.66)$ & $(0.88)$ & $(0.88)$ & $(1.01)$ & (0.99) \\
\hline \multicolumn{7}{|l|}{ Schooling at Age 20/21 (coef. X 100) } \\
\hline \multirow[t]{2}{*}{ Primary schooling (4 years) } & & -0.20 & & -0.22 & & \\
\hline & & $(2.17)$ & & $(2.00)$ & & \\
\hline \multirow[t]{2}{*}{ Lower intermediate (6 years) } & & 4.45 & & & & \\
\hline & & (2.19) & & & & \\
\hline \multirow[t]{2}{*}{ Intermediate ( 9 years) } & & 18.18 & & & & 13.73 \\
\hline & & $(2.36)$ & & & & $(1.21)$ \\
\hline \multirow[t]{2}{*}{ Secondary (12 years) } & & 21.32 & & & & 16.86 \\
\hline & & $(2.57)$ & & & & $(1.69)$ \\
\hline Number of Observations & & & & & & \\
\hline
\end{tabular}

Note: Standard errors in parentheses. Dependent variable is log of hourly wage at age $20 / 21$. For conscripts wage is measured on last job held before service. For nonconscripts wage is measured on job in 1988. Years of completed schooling are taken from employer report for job that is taken as pre-conscription job. Omitted category is less than primary schooling. See text for further details.

Table 4: Estimated Wage Effects of Conscription from Alternative Models

\begin{tabular}{|c|c|c|c|c|c|c|c|c|}
\hline & \multicolumn{2}{|c|}{$\begin{array}{c}\text { OLS, No Control } \\
\text { for Wage at } \\
\text { Age } 20 / 21\end{array}$} & \multicolumn{2}{|c|}{$\begin{array}{c}\text { OLS, Controling } \\
\text { for Wage at } \\
\text { Age } 20 / 21\end{array}$} & \multicolumn{2}{|c|}{$\begin{array}{c}\text { Differenced Model: } \\
\text { Wage Minus Wage } \\
\text { at Age } 20 / 21\end{array}$} & \multicolumn{2}{|c|}{$\begin{array}{c}\text { Quasi-Diff. Model: } \\
\text { Wage - } 2.62 \text { Wage } \\
\text { at Age } 20 / 21\end{array}$} \\
\hline & $\begin{array}{l}\text { Conscript. } \\
\text { Effect } \\
(1)\end{array}$ & $\begin{array}{l}\text { Std. } \\
\text { Error } \\
(2)\end{array}$ & $\begin{array}{l}\text { Conscript. } \\
\text { Effect } \\
\text { (3) }\end{array}$ & $\begin{array}{l}\text { Std. } \\
\text { Error } \\
(4)\end{array}$ & $\begin{array}{l}\text { Conscript. } \\
\text { Effect } \\
(5)\end{array}$ & $\begin{array}{l}\text { Std. } \\
\text { Error } \\
(6)\end{array}$ & $\begin{array}{c}\text { Conscript. } \\
\text { Effect } \\
(7)\end{array}$ & $\begin{array}{l}\text { Std. } \\
\text { Error } \\
(8)\end{array}$ \\
\hline \multicolumn{9}{|l|}{ a) Overall Sample } \\
\hline Pooled 1991-2000 & 1.1 & $(0.9)$ & 0.9 & $(0.8)$ & 0.6 & (0.9) & -0.2 & (2.0) \\
\hline Pooled 2002-2009 & 2.1 & $(1.2)$ & 2.1 & $(1.2)$ & 2.0 & (1.3) & 1.9 & (2.3) \\
\hline \multicolumn{9}{|l|}{ b) Low Education } \\
\hline Pooled 1991-2000 & 0.6 & $(1.2)$ & 0.6 & (1.1) & 0.7 & (1.3) & 0.8 & (2.7) \\
\hline Pooled 2002-2009 & 4.1 & $(1.7)$ & 4.1 & $(1.6)$ & 4.3 & $(1.8)$ & 4.5 & (3.2) \\
\hline \multicolumn{9}{|l|}{ c) High Education } \\
\hline Pooled 1991-2000 & 1.5 & (1.3) & 1.0 & $(1.2)$ & 0.5 & (1.4) & -1.1 & (2.8) \\
\hline Pooled 2002-2009 & 0.5 & $(1.8)$ & 0.4 & $(1.7)$ & 0.3 & (1.9) & -0.1 & (3.1) \\
\hline
\end{tabular}

Notes: Estimated coefficients times 100 (with standard errors clustered by person in parenthesis). Pooled estimates use sample of available person-year observations and include dummies for year and for education as of age 20 or 21 . Models in columns 3-4 include wage measured at age 20 or 21. Models in columns 5-6 use as dependent variable wage at indicated year, minus wage at age 20/21. Models in columns 7-8 use as dependent variable wage at indicated year minus 2.62 times wage at age 20/21. Source: Portugal, MTSS (1986-2009). 
Table 5: Robustness CHecks: Estimated WAge EfFects of ConsCRiption for Years 2002-2009 from AlterNATIVE MODELS

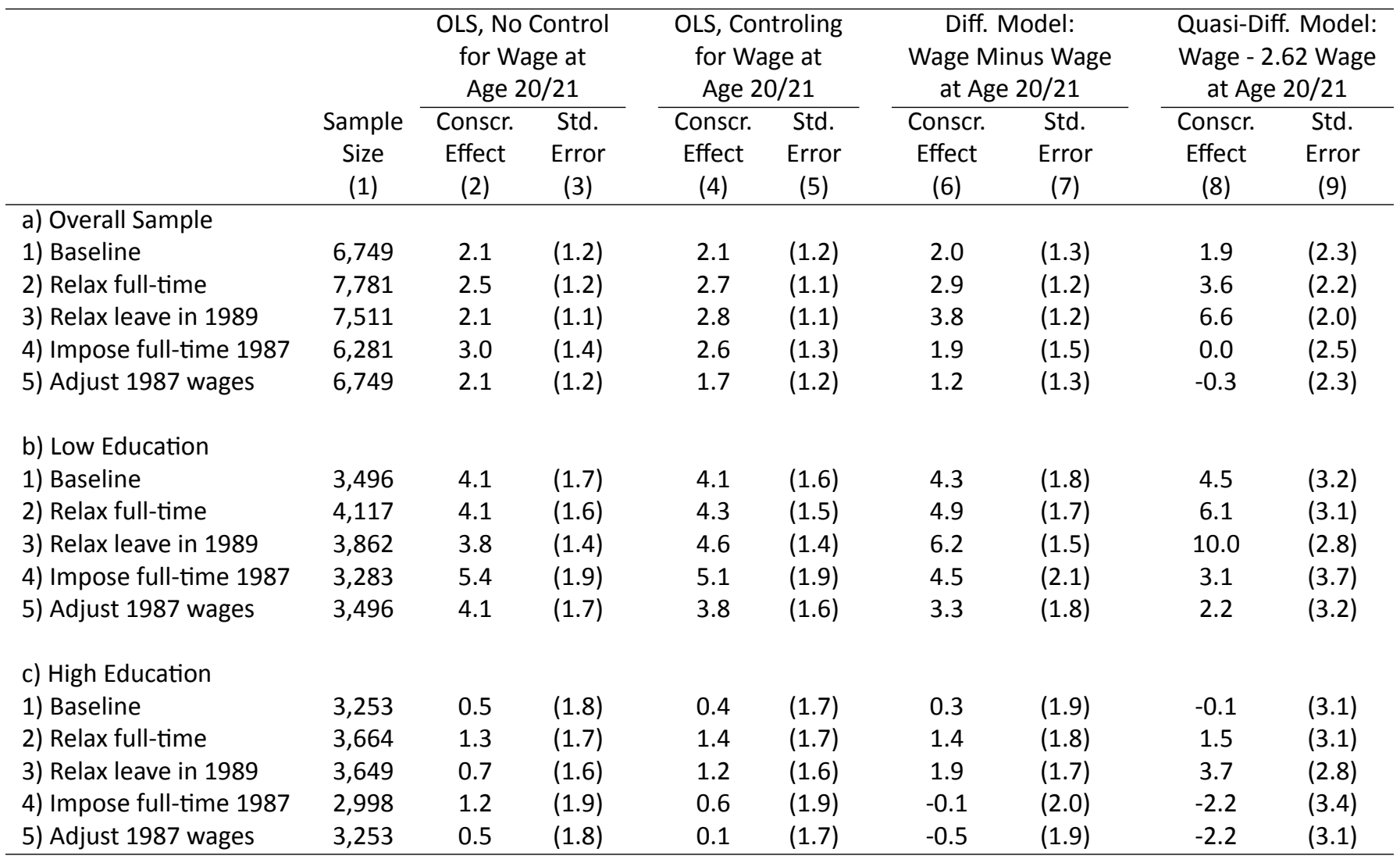

Notes: In the baseline sample, conscripts include men who were working full time in 1987 and on leave in 1988 and 1989, plus men who were working full time in 1988 and on leave in 1989. Non-conscripted men are those who were working full time in 1988 and 1989. Sample in rows 2 replaces "full time" work requirements for both groups with requirement that the individual be working and have a valid wage. Sample in rows 3 modifies conscript definition to include men who were working full time in 1987 and on leave in 1988, plus men who were working full time in 1988 and on leave in 1989, thus dropping the requirement that the men who worked full time in 1987 were also on leave in 1989. Sample in rows 4 modifies conscript definition to include men who were working full time in 1987 and on leave in 1988 and 1989, plus men who were working full time in both 1987 and 1988 and on leave in 1989, thus limiting the second group to those who were working full time in both 1987 and 1988. Sample in rows 5 is same as baseline. However, wages of conscripts who were working full time in 1987 and on leave in 1988 and 1989 are inflated by 4.4\%. Estimated coefficients times 100 (with standard errors in parentheses). All models include dummies for year and education as of age 20 or 21 . Models in columns 4-5 include wage measured at age 20 or 21 . Models in columns 6-7 use as dependent variable wage at indicated age minus wage at age 20/21. Models in columns 8-9 use as dependent variable wage at indicated age minus 2.62 times wage at age 20/21. Estimates use sample of available person-year observations. Standard errors are clustered by person. Source: Computations based on Portugal, MTSS (1986-2009). 
Table 6: Change IN EduCATION

\begin{tabular}{|c|c|c|c|c|c|c|}
\hline & \multicolumn{2}{|c|}{ All } & \multicolumn{2}{|c|}{ Low-Education } & \multicolumn{2}{|c|}{ High-Education } \\
\hline & (1) & $(2)$ & (3) & $(4)$ & $(5)$ & $(6)$ \\
\hline \multirow[t]{2}{*}{ Conscription Dummy } & 0.07 & 0.14 & 0.22 & 0.26 & 0.05 & 0.04 \\
\hline & $(0.05)$ & $(0.05)$ & (0.09) & (0.09) & $(0.06)$ & $(0.06)$ \\
\hline \multicolumn{7}{|l|}{ Schooling at Age 20/21: } \\
\hline \multirow[t]{2}{*}{ Less than primary schooling } & & 2.54 & & 1.80 & & \\
\hline & & $(0.21)$ & & $(0.2)$ & & \\
\hline \multirow[t]{2}{*}{ Primary schooling (4 years) } & & 0.76 & & & & \\
\hline & & $(0.11)$ & & & & \\
\hline \multirow[t]{2}{*}{ Lower intermediate (6 years) } & & 0.30 & & & & 0.31 \\
\hline & & $(0.12)$ & & & & $(0.1)$ \\
\hline \multirow[t]{2}{*}{ Intermediate ( 9 years) } & & 0.29 & & & & 0.30 \\
\hline & & $(0.14)$ & & & & $(0.12)$ \\
\hline Mean & \multicolumn{2}{|c|}{0.77} & \multicolumn{2}{|c|}{1.04} & \multicolumn{2}{|c|}{0.50} \\
\hline Standard Deviation & \multicolumn{2}{|c|}{1.68} & \multicolumn{2}{|c|}{1.86} & \multicolumn{2}{|c|}{1.43} \\
\hline Obs. & \multicolumn{2}{|c|}{4,903} & \multicolumn{2}{|c|}{2,459} & \multicolumn{2}{|c|}{2,444} \\
\hline
\end{tabular}

Note: Standard errors in parentheses. Sample includes conscripts and nonconscripts who were observed working as a wage earner in the QP at least once between 2002 and 2009. Dependent variable is change in schooling from last observed value (in 2002-2009 period) to initial value at age 20/21. Omitted category is completed secondary schooling (12 years). Source: Computations based on Portugal, MTSS (1986-2009). 
Figure 1: Labor Market Situation, Conditional on Working Full-time the Year before Military EnListMENT DUE

cohort 1967, males

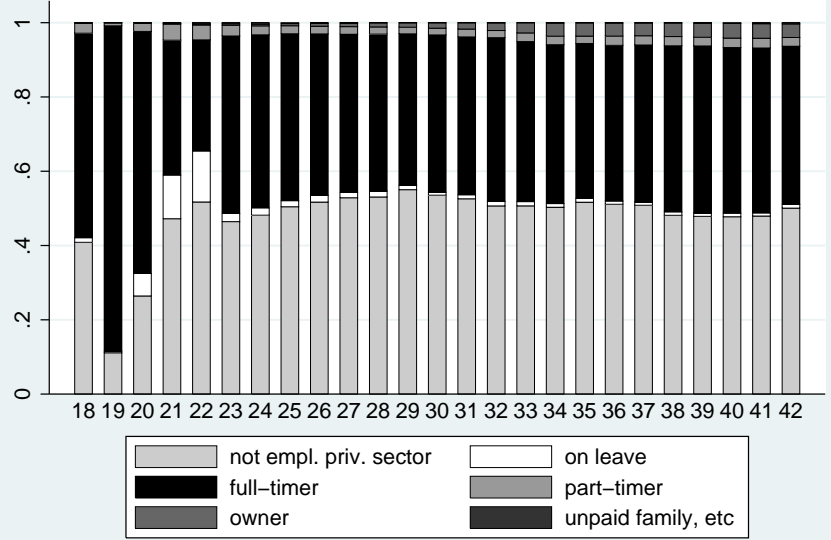

cohort 1977, males

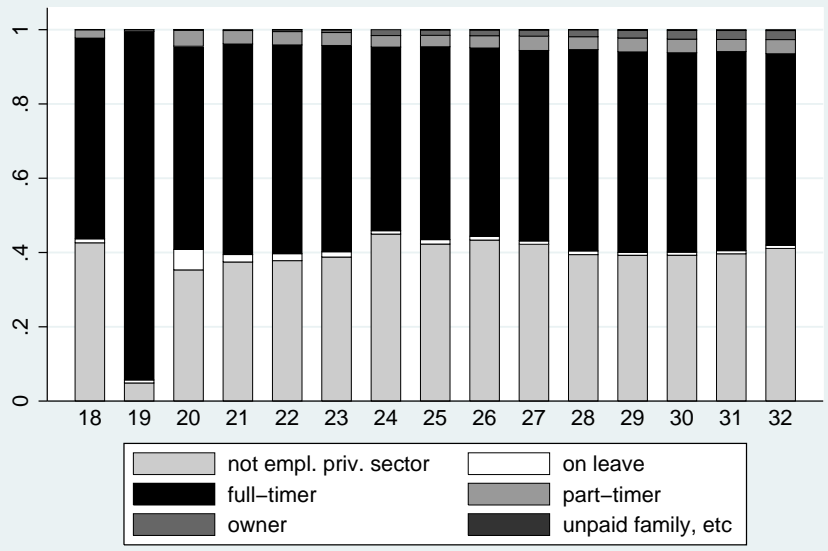

cohort 1987, males

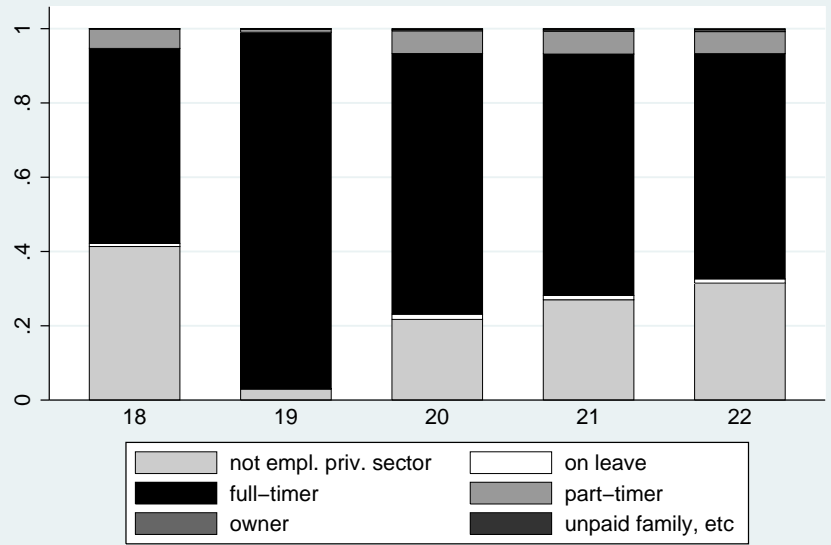

cohort 1967, females

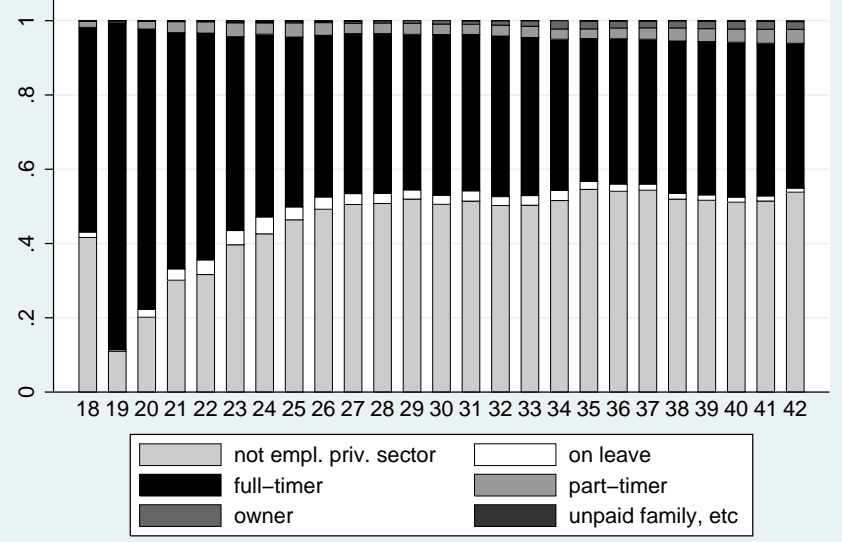

cohort 1977, females

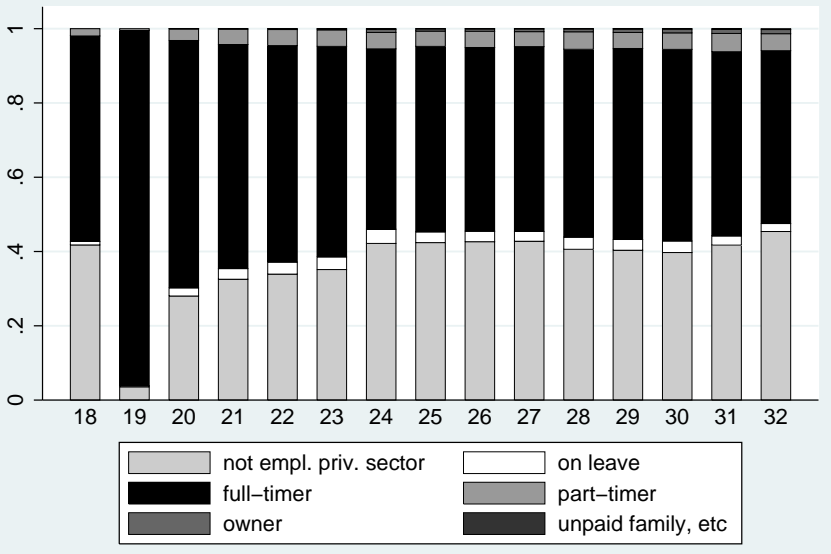

cohort 1987, females

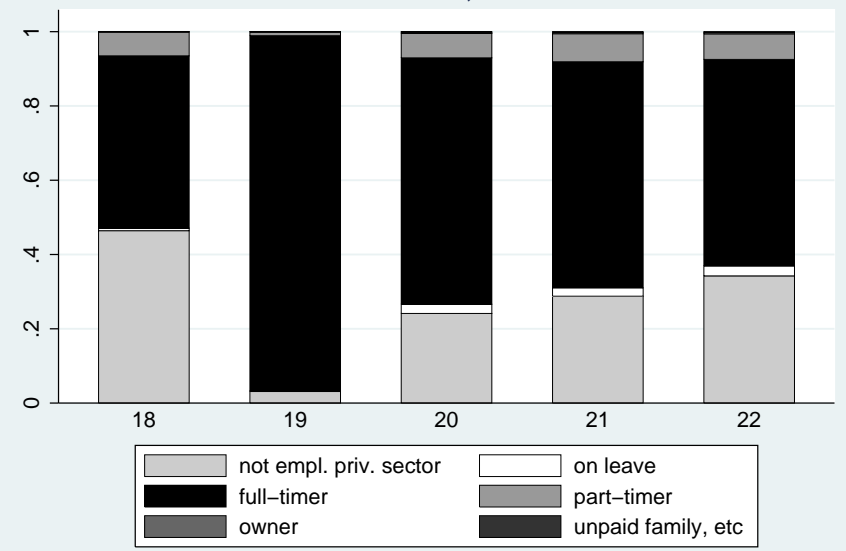

Note: For the 1967 cohort (first row), military enlistment was due the year the individual turned 21 (thus observed the year before, at age 20 or 19 depending on the date of birth) and service lasted for 24 months; for the 1977 cohort (second row), enlistment was due the year the individual turned 20 and service lasted for 4 months; for the 1987 cohort (third row), military enlistment had been abolished and the plot is conditional on working full-time the year the individual turned 20. Source: Computations based on Portugal, MTSS (1986-2009). 
Figure 2: Wages at Age 20/21 and Wages at Midcareer for Men Born in 1967

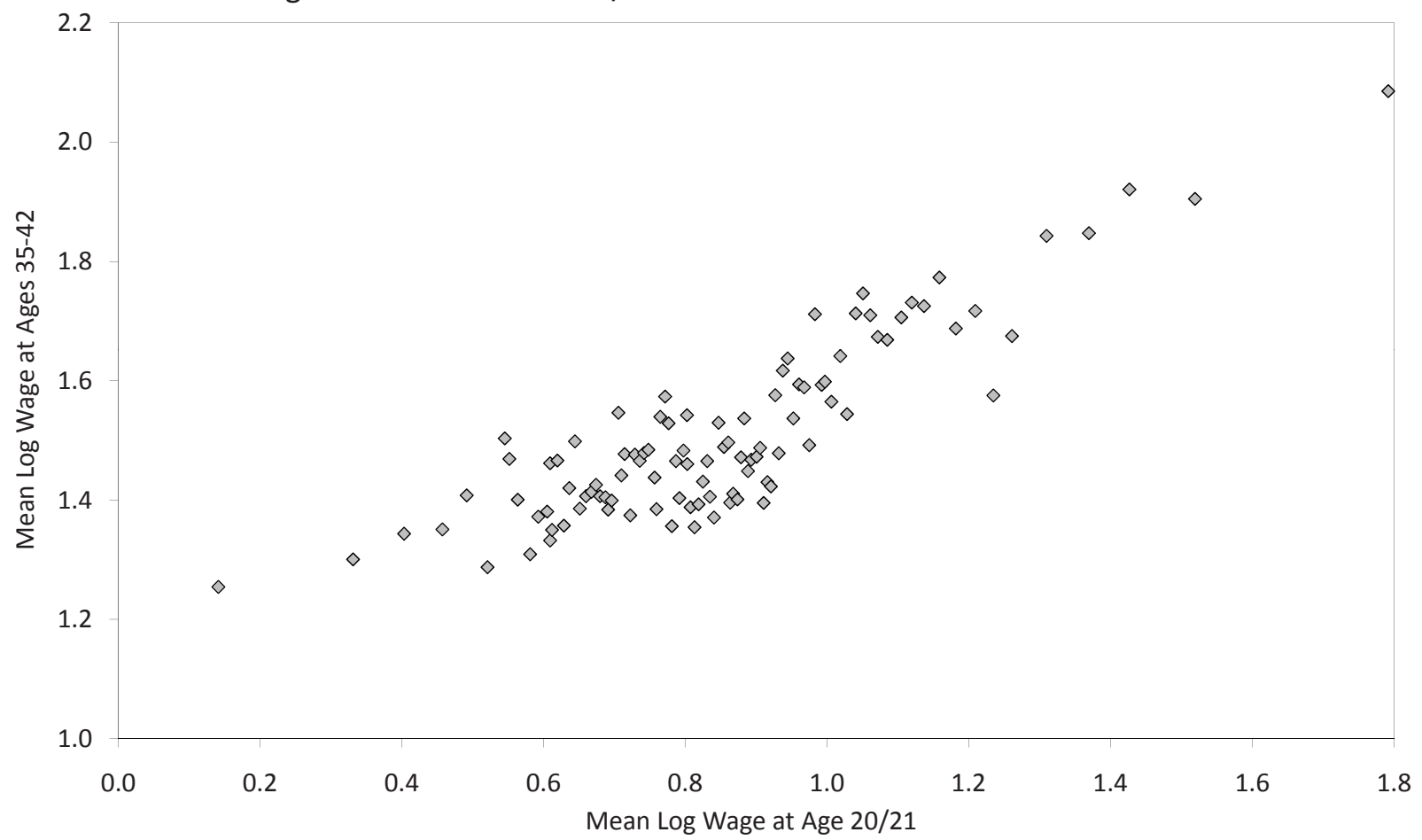

Note: each point in the graph is a percentile group (based on wages at age 20/21) and includes about 67 workers. 
Figure 3a: Age Profiles of Hourly WAges for ConsCRIPTS AND NON-CONSCRIPTS

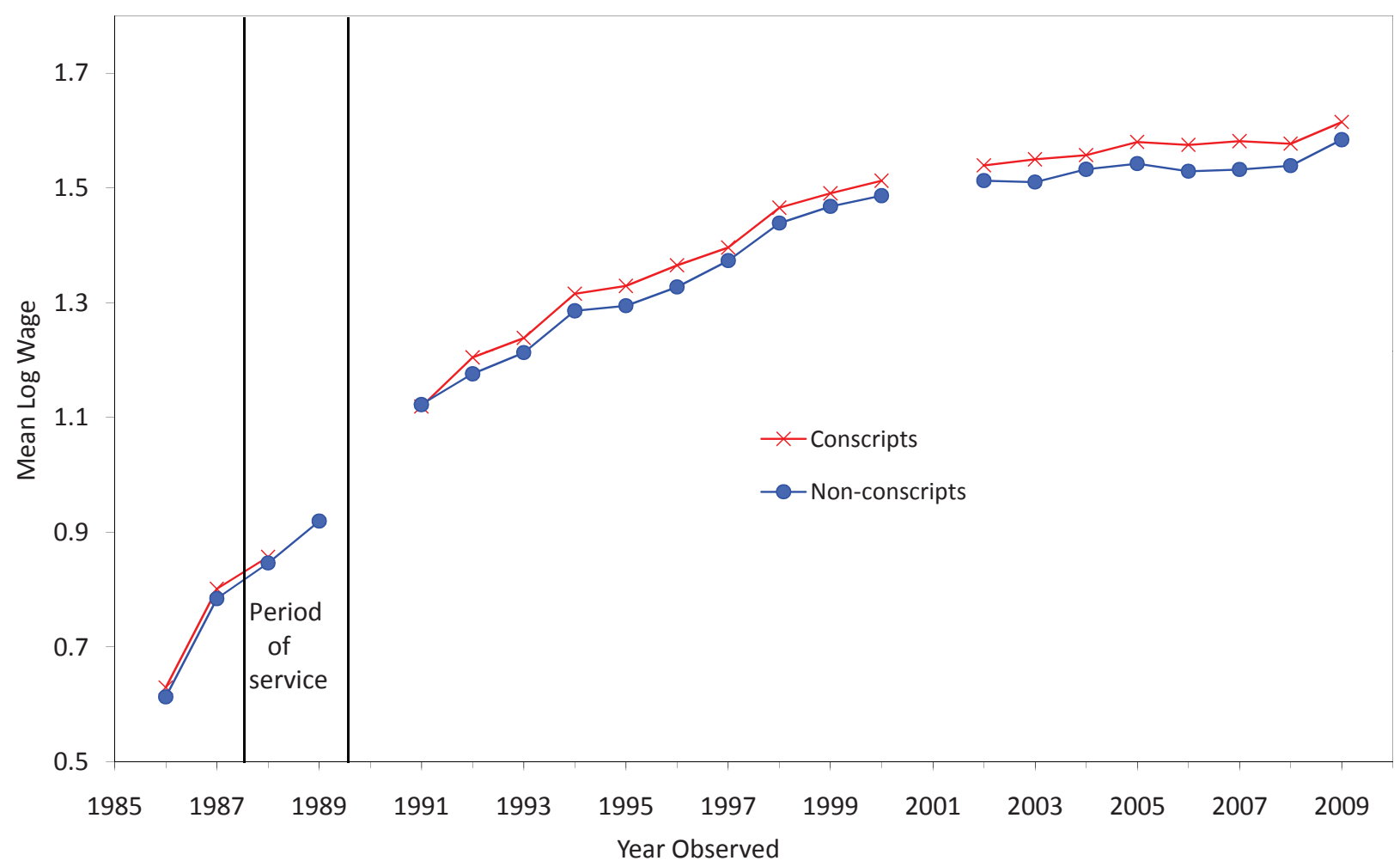

Note: Conscripted is an individual working full-time in 1987 or 1988 and reported on leave during the years military enlistment is due; non-conscripted is an individual observed working full-time during the years military enlistment is due. For the cohort born 1967, military enlistment was due the year the individual turned 21 and it lasted for 24 months. Source: Computations based on Portugal, MTSS (1986-2009). 
Figure 3b: Age Profiles of HOURLY WAgeS For LOW-EduCATION CONSCRIPTS AND NON-CONSCRIPTS

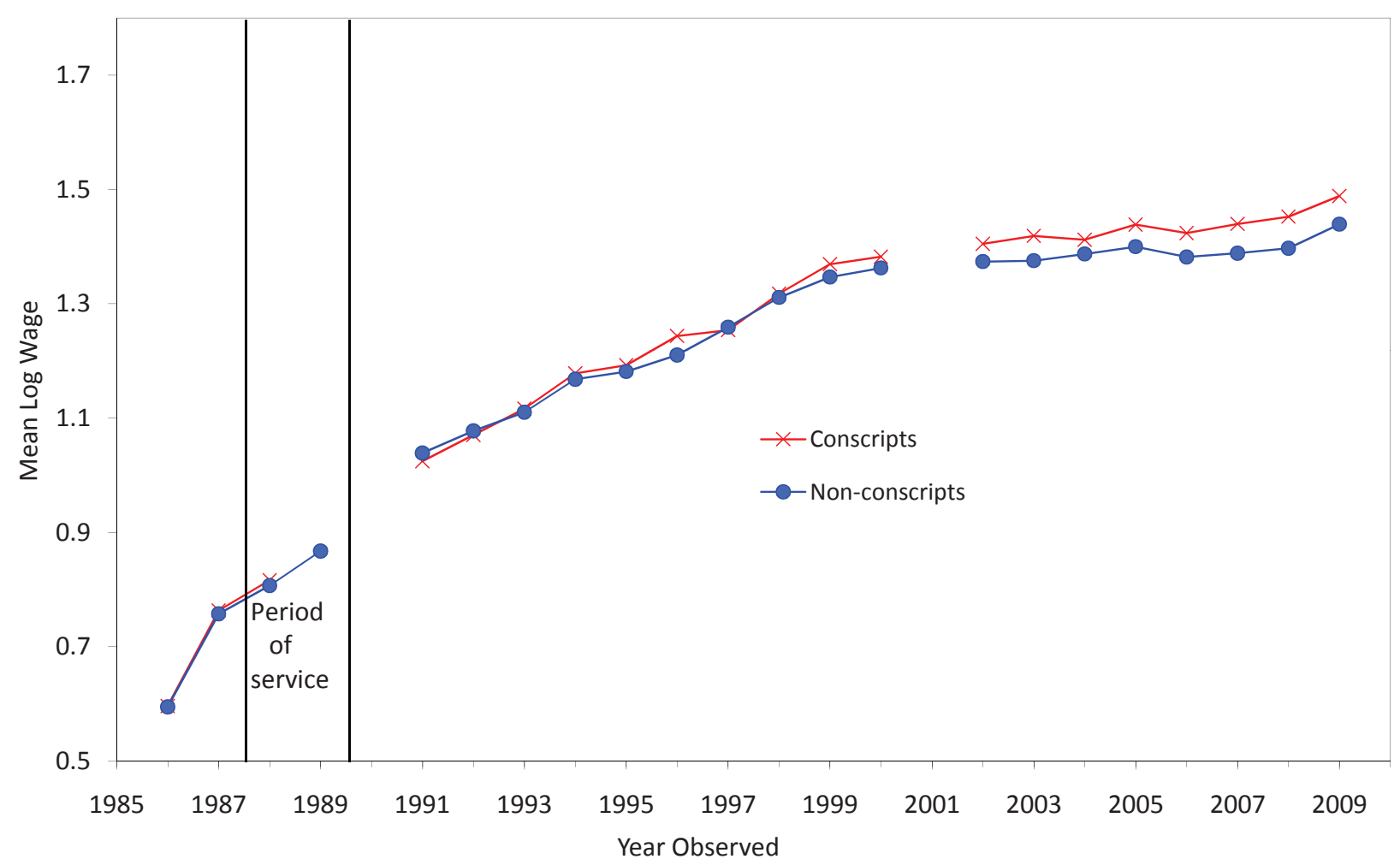

Note: Conscripted is an individual working full-time in 1987 or 1988 and reported on leave during the years military enlistment is due; non-conscripted is an individual observed working full-time during the years military enlistment is due. For the cohort born 1967, military enlistment was due the year the individual turned 21 and it lasted for 24 months. Source: Computations based on Portugal, MTSS (1986-2009). 
Figure 3c: Age Profiles of Hourly Wages for High-Education CONSCRIPTS AND NON-CONSCRIPTS

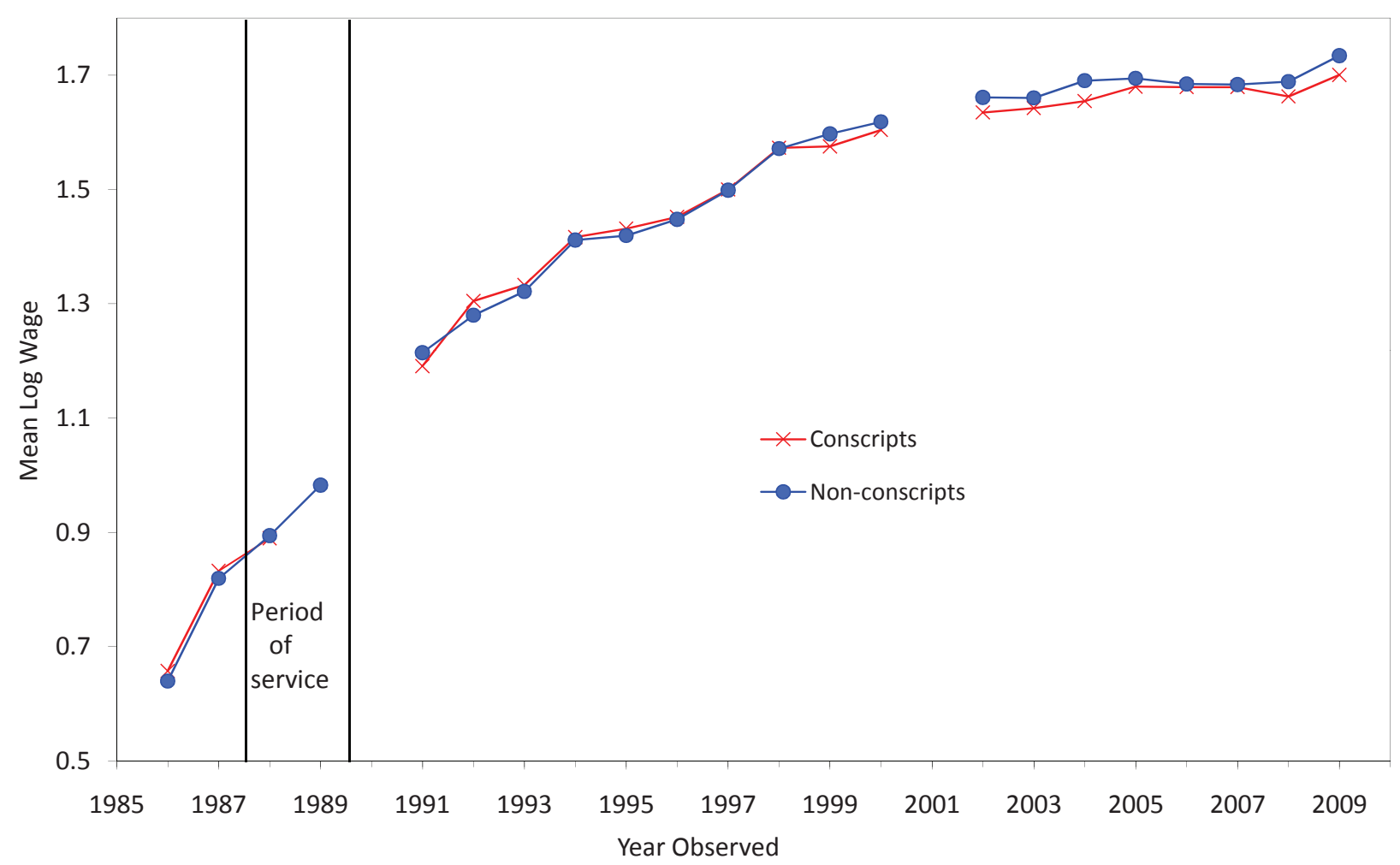

Note: Conscripted is an individual working full-time in 1987 or 1988 and reported on leave during the years military enlistment is due; non-conscripted is an individual observed working full-time during the years military enlistment is due. For the cohort born 1967, military enlistment was due the year the individual turned 21 and it lasted for 24 months. Source: Computations based on Portugal, MTSS (1986-2009). 
Figure 4a: Age Profiles of EMPLOYMENT FOR CONSCRIPTS AND NON-CONSCRIPTS

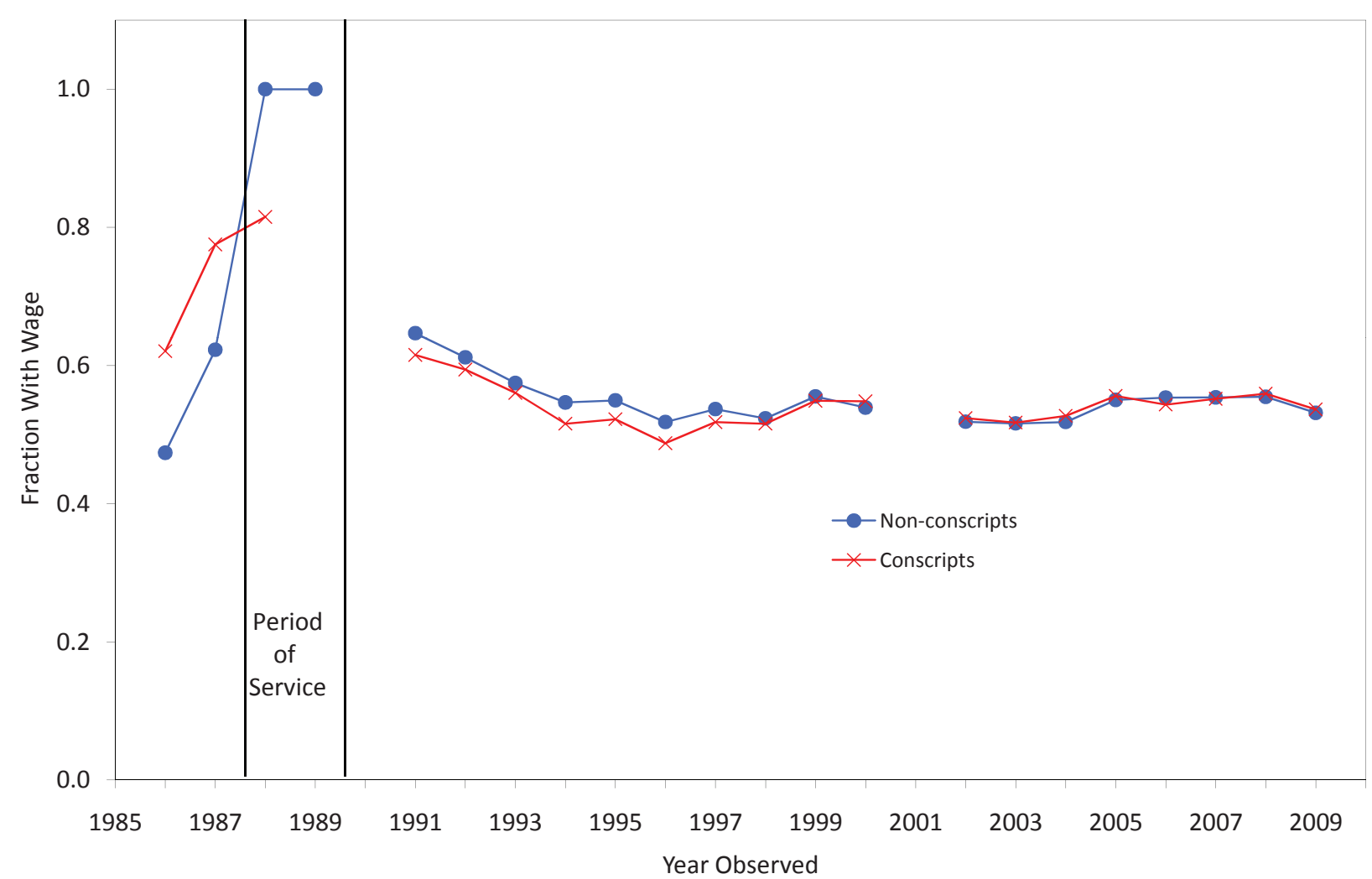

Note: Conscripted is an individual working full-time in 1987 or 1988 and reported on leave during the years military enlistment is due; non-conscripted is an individual observed working full-time during the years military enlistment is due. For the cohort born 1967, military enlistment was due the year the individual turned 21 and it lasted for 24 months. Source: Computations based on Portugal, MTSS (1986-2009). 
Figure 4b: Age Profiles of EMPLOYMent for LOW-EDUCATION CONSCRIPTS AND NON-CONSCRIPTS

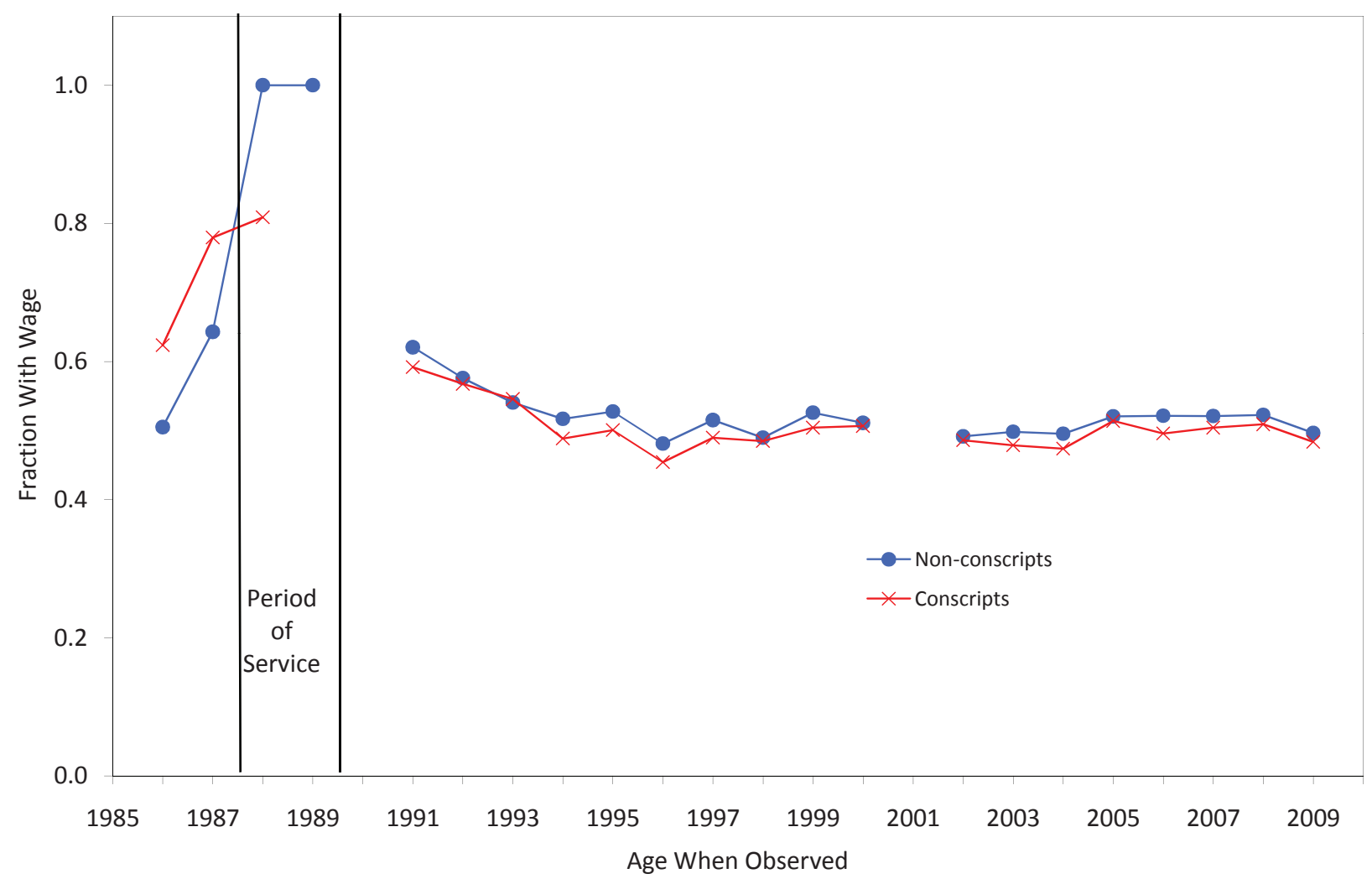

Note: Conscripted is an individual working full-time in 1987 or 1988 and reported on leave during the years military enlistment is due; non-conscripted is an individual observed working full-time during the years military enlistment is due. For the cohort born 1967, military enlistment was due the year the individual turned 21 and it lasted for 24 months. Source: Computations based on Portugal, MTSS (1986-2009). 
Figure 4c: Age Profiles of EMPlOYMent for High-EducAtion CONSCRIPTS AND NON-CONSCRIPTS

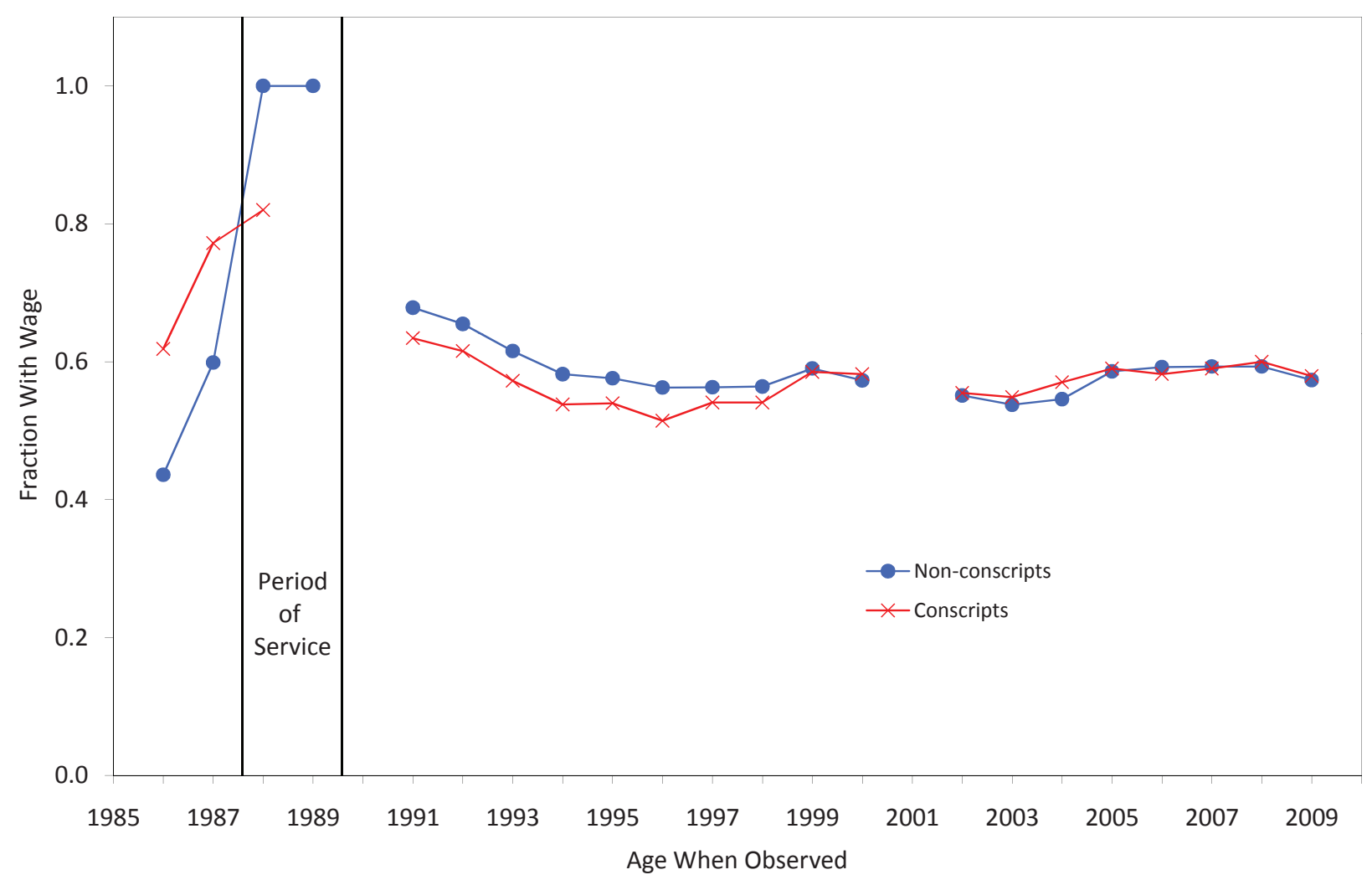

Note: Conscripted is an individual working full-time in 1987 or 1988 and reported on leave during the years military enlistment is due; non-conscripted is an individual observed working full-time during the years military enlistment is due. For the cohort born 1967, military enlistment was due the year the individual turned 21 and it lasted for 24 months. Source: Computations based on Portugal, MTSS (1986-2009). 
Figure 5: ESTIMATED IMPACT OF ENLISTMENT AT AGES 35-42, QUASI-DIFFERENCING WAGE REGRESSIONS WITH ALTERNATIVE VALUES OF THE DIFFERENCING FACTOR
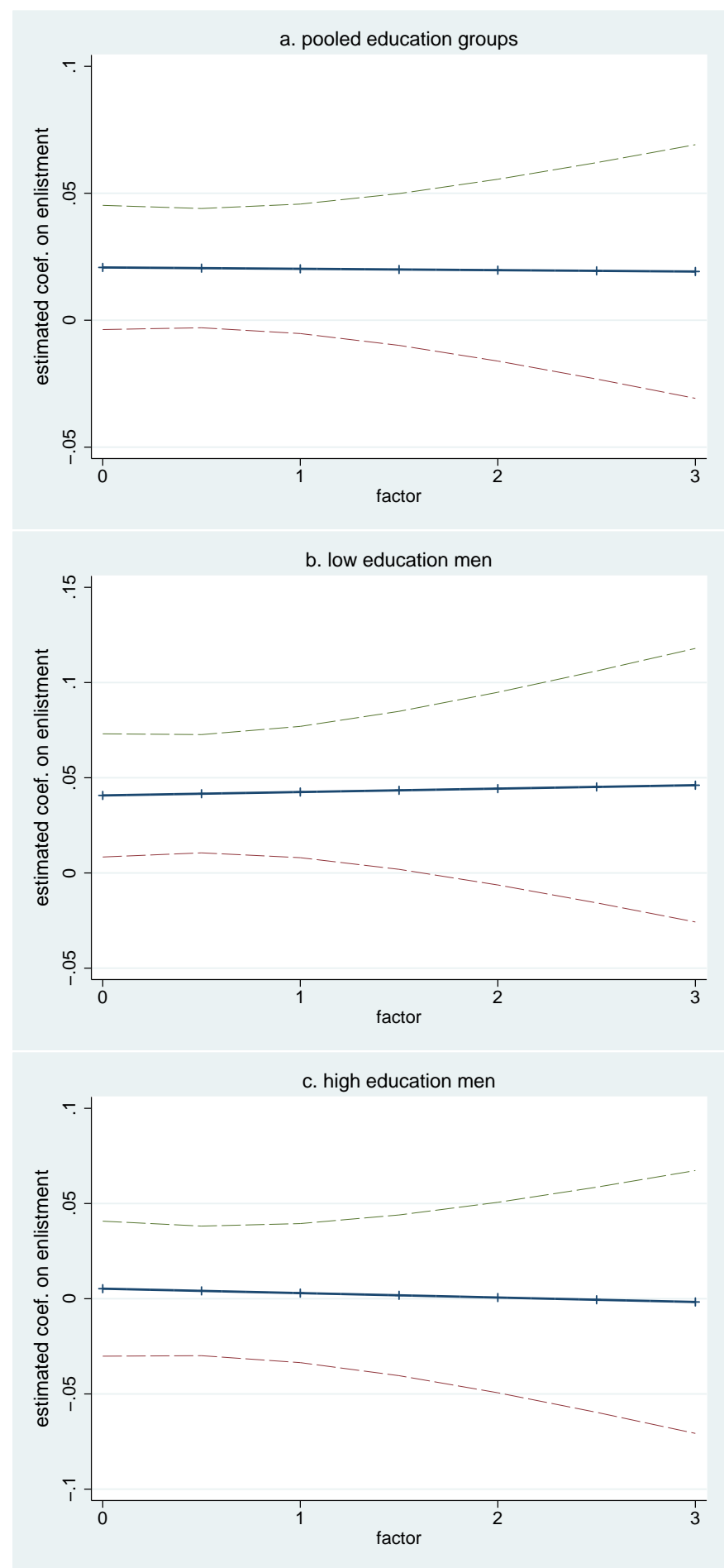

Source: Computations based on Portugal, MTSS (1986-2009). 
Figure 6: INTERCOHORT COMPARISONS OF CONSCRIPTION RATE AND WAGES

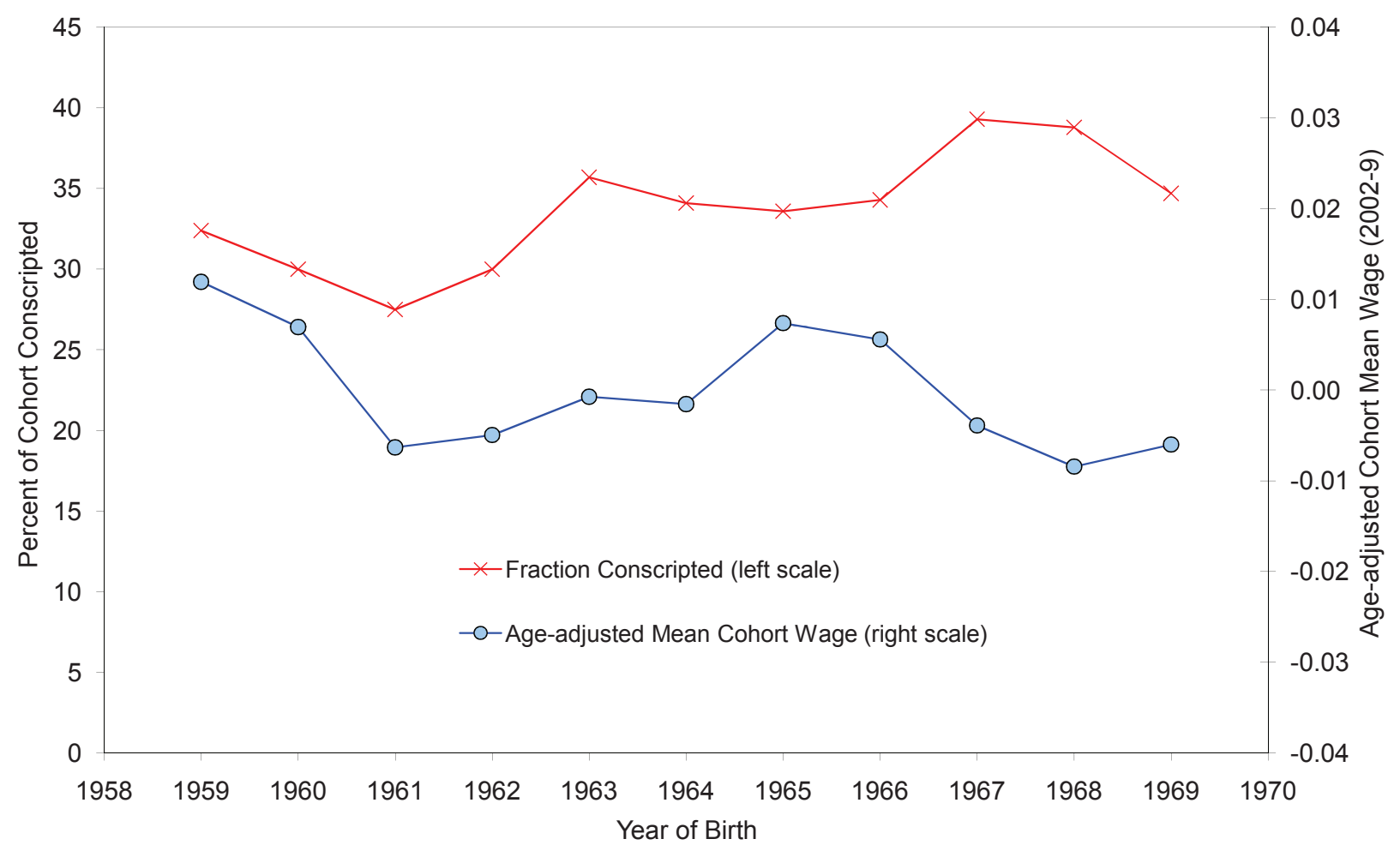

Source: Computations based on Portugal - MTSS (1986-2009), Baganha and Marques (2001), and Portugal - Estado Maior do Exército (2000). 


\section{Appendix}

\section{Dataset}

Quadros de Pessoal (QP) data are gathered annually by the Portuguese Ministry of Employment. All firms with wage-earners are required to complete the survey. Civil servants and household workers are excluded from coverage. The coverage of agriculture is also relatively low, given its low share of wage-earners. The mandatory nature of the survey leads to extremely high response rates, and in recent years nearly all firms with wage-earners in manufacturing and services are included in the data set. Nevertheless, there was some under-coverage -particularly of very small firms- in the initial years of the QP (Portugal, MTSS, 1990).

All personnel working in the firm in a reference week (in March until 1993 and in October from 1994 onwards) are in-scope for the QP. Workers on short-term leave (e.g., sickness, maternity leave, vacation, and strikes) and those on leave for compulsory military service are also supposed to be reported. Appendix Table A.1 clarifies the coding of leaves of absence during the period under analysis.

Reported data in the QP include the firm's location, industry, employment, sales, ownership (private Portuguese-owned, private foreign-owned, or public-owned), incorporation status, and the worker's gender, age, occupation, schooling, date of hire, monthly earnings (split into several components), and hours of work. Schooling information pertains to the highest completed level of education, with the following categories: first cycle or primary education (4 years); second cycle (6 years); third cycle (9 years); high school (12 years); university. ${ }^{1}$

Workers are assigned an identification number, based on a transformation of the social security number, that enables tracking over time. Similarly, each firm entering the database is assigned a unique identification number and it can be followed over time. The Ministry implements several checks to ensure that a firm that has already reported to the database is not assigned a different identification number. Most of these routines are based on the detailed location of the company and its legal identification codes.

\section{Merging data across years}

We combine QP data for the period from 1986 to 2009. The following data checks and selection procedures were implemented to prepare a worker-level data set to be merged

\footnotetext{
${ }^{1}$ Since the mid-1990s, these categories, and in particular the two highest categories, are further subdivided.
} 
across years.

Selection of valid worker identification codes: Observations with missing or invalid worker identification codes have been dropped. This restriction led to dropping an average $5.5 \%$ percent of the observations in the original yearly data sets made available by the Ministry of Employment.

Handling of duplicate worker identification codes in a given year: Only workers whose identification number appears at a maximum of two different firms are included in the annual file we use to build a longitudinal file. This allows workers to have a maximum of two jobs during the reference week. In the case of a duplicate observation in any year, we also checked that the worker's gender, date of birth, and schooling were the same in both jobs - otherwise the observations were dropped. On average 0.6 percent of the original observations in the annual QP files are dropped because the worker appeared at 3 or more firms; 2.7 percent of the observations were dropped because the worker appeared at two firms but had different gender, age or schooling in the two jobs; and 0.1 percent of the observations were dropped because the worker was reported twice by the same firm.

After these data checks, on average 91 percent of the observations in the original yearly data sets are retained, yielding an initial panel of 50,847,109 person-year observations on $7,963,035$ workers.

\section{Checks on the consistency of the longitudinal data}

We imputed age and/or schooling to missing observations whenever there was no obvious inconsistency in the reported values. ${ }^{2}$ These imputations affected 1.2 percent and 0.9 percent of the observations in the initial panel, respectively for age and schooling.

Inconsistencies were identified if the worker's gender or date of birth was reported as changing, or if the highest schooling level was reported as decreasing over time. In such cases, the value reported in over $50 \%$ of the non-missing records was treated as the correct value (if there was such a value). Using this procedure, 0.8 percent, 2.5 percent and 7.7 percent of the observations in the initial panel were corrected for inconsistencies in reported gender, birth date and education, respectively. In cases where no value was reported more than half the time, the individual was dropped from the panel. Overall, 1.5 percent, 0.8 percent and 6.2 percent of the observations are dropped due to inconsistent

\footnotetext{
${ }^{2}$ If schooling was consistently reported (possibly increasing over time) and the values it achieved before and after a missing year were the same, the missing value was corrected; similarly, missings in the initial/final period(s) were extrapolated from the earliest/latest reported value.
} 
information on gender, birth date or schooling, respectively.

Finally, any remaining workers with missing age or schooling were dropped (0.3 percent and 1.7 percent of the initial panel, respectively).

The final panel data set includes 45,511,769 person-year observations for 7,159,178 workers: this represents approximately 90 percent of the initial panel.

A final set of checks on the longitudinal data concentrated on the date of hire information. Dates of hire later than the date of the survey reference week were considered as mistakes and recoded to missing (affecting $3.8 \%$ of the observations). Missing information on date of hire was imputed whenever it was consistently reported for other years in the spell (affecting $4.6 \%$ of the observations). When the information was reported inconsistently across years, the date of hire reported more than one-half the time was taken as the correct one, leading to corrections for $2.1 \%$ of the observations. If after these corrections a worker had two or more dates of hire within the same employment spell the first reported date was considered the correct date (correcting $0.9 \%$ of the observations). Workers with inconsistent data after the introduction of the previous corrections were assigned missing information on date of hire ( $0.1 \%$ of the observations).

\section{Sources of Information on Military Service}

In the text and tables we present information on various aspects of military service. Our primary sources for this information are as follows:

On regulations governing military service:

- Portugal. Assembleia da República (1987). Law 30/87, July 7.

- Portugal. Assembleia da República (1991). Law 22/91, June 19.

- Portugal. Ministério da Defesa Nacional (1988). Decree-law 463/88, December 15.

- Portugal. Presidência da República (1968). Law 2135, July 11.

On the recording of men in military service in the QP:

- Portugal. Ministério do Trabalho (1980). Decree-law 380/80, September 17. 


\section{Estimation of Covariance Model for Wage Residuals}

In this appendix we discuss our methods for estimating the parameters $\psi_{t}$. The reduced form wage residuals for individual $i$ in period $t$ are assumed to be generated by the model:

$$
v_{i t}=\psi_{t} \eta_{i}+\epsilon_{i t} \quad t=0,1, \ldots T
$$

with $\psi_{0}=1$. Under this model the variance-covariance matrix of the residuals has elements:

$$
\begin{aligned}
\operatorname{var}\left[v_{i t}\right] & =\left(\psi_{t}\right)^{2} \sigma_{\eta}^{2}+\operatorname{var}\left[\epsilon_{i t}\right] \\
\operatorname{cov}\left[v_{i t}, v_{i s}\right] & =\psi_{t} \psi_{s} \sigma_{\eta}^{2}+\operatorname{cov}\left[\epsilon_{i t}, \epsilon_{i s}\right]
\end{aligned}
$$

where $\sigma_{\eta}^{2}=\operatorname{var}\left[\eta_{i}\right]$ is the variance of the permanent ability component. We assume that the transitory shocks $\epsilon_{t}$ are generated by a stationary first-order autoregressive process:

$$
\epsilon_{i t}=\rho \epsilon_{i t-1}+\zeta_{i t}
$$

with

$$
\operatorname{var}\left[\zeta_{i t}\right]=\sigma_{\zeta}^{2}
$$

and an arbitrary value for the variance of $\epsilon_{i 0}$ :

$$
\operatorname{var}\left[\epsilon_{i 0}\right]=\sigma_{0}^{2}
$$

To allow for additional potential non-stationarity at the start of the work-life, we also assume that the pre-conscription wage residual contains an additive component:

$$
v_{i 0}=\eta_{i}+\epsilon_{i 0}+\kappa_{i 0},
$$

where $\operatorname{var}\left[\kappa_{i 0}\right]=\sigma_{\kappa}^{2}$, and $\kappa_{i 0}$ is uncorrelated with $\eta_{i}$ or the sequence of transitory shocks. Finally we assume that $\psi_{t}$ rises linearly for $\bar{t}=14$ years, and thereafter remains constant:

$$
\begin{array}{rlr}
\psi_{t} & =1+g t \quad 0 \leq t \leq 14 \\
& =\bar{\psi}=1+g \bar{t} \quad t>14 .
\end{array}
$$

Under these assumptions the 190 elements of the $19 \times 19$ variance covariance matrix of the wage residuals for the pre-conscription wage $w_{0}$ and the post-conscription wages in 1991-2000 plus 2002-2009 can be written as a function of underlying parameter vector $\theta=\left\{\bar{\psi}, \sigma_{\eta}^{2}, \sigma_{\zeta}^{2}, \sigma_{0}^{2}, \sigma_{\kappa}^{2}, \rho\right\}$. Letting 


$$
\widehat{m}_{i s t}=\widehat{v}_{i t} \widehat{v}_{i s}
$$

represent the product of the estimated reduced form errors for individual $i$ in periods $s$ and $t$, the estimated variance covariance matrix has $(s, t)$ element:

$$
\widehat{m}_{s t}=\frac{1}{N_{s t}} \sum_{i} \widehat{m}_{i s t}
$$

where $N_{s t}$ is the number of observations with observed wages in periods $s$ and $t$. Let $\widehat{m}$ $=v e c\left[\widehat{m}_{s t}\right]$. Our model assumes that in the absence of sampling error the elements of $m$ will depend on the parameters $\theta$ :

$$
m=f(\theta) .
$$

We choose $\theta$ to minimize the sum of squared residuals $[\widehat{m}-f(\theta)]^{\prime}[\widehat{m}-f(\theta)]$, and use standard formulas to construct a matrix of sampling errors for the corresponding estimate. Our estimates (and standard errors) are as follows

$\begin{array}{ccc}\bar{\psi} & 2.616 & (0.16) \\ \sigma_{\eta}^{2} & 0.0132 & (0.002) \\ \sigma_{\zeta}^{2} & 0.0296 & (0.001) \\ \sigma_{0}^{2} & 0.0465 & (0.004) \\ \rho & 0.719 & (0.020) \\ \sigma_{\kappa}^{2} & 0.000 & --\end{array}$

We used these parameters to simulate wage data for a set of 6700 people over the same horizon as our sample (i.e., for the initial wage observation, and for the postconscription period from 1991 to 2009) and assumed that $28 \%$ of the data were missing at random in each year from 2002-2009. We then divided the sample into 100 percentile groups based on the initial (pre-conscription) wage, and constructed an average wages over the 2002-2009 period for each percentile group. Finally, we regressed the mean 2002-2009 wage for each percentile group on their average pre-conscription wage and obtained a regression coefficient of 0.54 with $R^{2}=0.88$. This compares to the actual data in Figure 2 which yields a regression coefficient of 0.53 and $R^{2}=0.77$. 
TABLE A.1: TYPES OF LEAVE AND THEIR CODING DURING THE PERIOD UNDER ANALYSIS

\begin{tabular}{|c|c|c|c|c|c|}
\hline \multirow{2}{*}{$\begin{array}{l}\text { Type of } \\
\text { Leave }\end{array}$} & \multirow{2}{*}{$\begin{array}{c}\text { Worker } \\
\text { Reported (1) }\end{array}$} & \multicolumn{2}{|c|}{ QP Coding of } & \multirow{2}{*}{$\begin{array}{l}\text { Coding of } \\
\text { "on Leave" }\end{array}$} & \multirow[t]{2}{*}{ Notes } \\
\hline & & Wage & Hours & & \\
\hline Sickness & yes & $\begin{array}{l}\text { missing, } \\
\text { if leave } \\
\text { longer } \\
\text { than } 3 \\
\text { days }\end{array}$ & $\begin{array}{l}\text { missing, } \\
\text { if leave } \\
\text { longer } \\
\text { than } 3 \\
\text { days }\end{array}$ & $=1$ & $\begin{array}{l}\text { Wage paid (approx. } 65 \% \text { of normal wage) } \\
\text { by the social security, after } 3 \text { days of sick- } \\
\text { ness. Estimated overall rate of sickness ab- } \\
\text { senteeism in Portugal: } 8 \% \text { (EFILWC, 1997, } \\
\text { p. 18). }\end{array}$ \\
\hline Maternity & yes & missing & missing & $=1$ & $\begin{array}{l}\text { Maternity leave started in Portugal in1976, } \\
\text { when it lasted for } 90 \text { days. Currently, it } \\
\text { lasts for } 120 \text { days. }\end{array}$ \\
\hline Strike & yes & missing & missing & $=1$ & $\begin{array}{l}\text { Average of } 0.016 \% \text { work days lost per } \\
\text { year during } 1986-1996 \text { (own computations } \\
\text { based on Portugal, INE (2011) and Pordata } \\
(2011) \text { ). }\end{array}$ \\
\hline Holiday & yes & reported & reported & $=0$ & \\
\hline Military & yes & missing & missing & $=1$ & \\
\hline
\end{tabular}

Note: (1) Instructions to fill out the questionnaire during the 1980s and 1990s stated that everyone engaged in the firm during the reference period should be listed, including: "the owner of the firm, if performing a function in the firm; unpaid and paid family members, if working in the firm more than one third of the normal duration of work; piece-rate workers; workers on short-term leave and those doing their military service" (Portugal, MT, Decree-Law 380/80, instructions on filling out column 2 of the Quadros de Pessoal form) [own translation]. Elsewhere in the instructions form, examples of short term leave are provided: sickness, maternity, holiday, strike. 
Table A2.a: Estimated Wage Effects of Conscription at Various Ages from Alternative Models (Pooled Education Groups)

\begin{tabular}{|c|c|c|c|c|c|c|c|c|c|}
\hline \multirow[b]{2}{*}{ Year } & \multirow{2}{*}{$\begin{array}{l}\text { Modal } \\
\text { Age }\end{array}$} & \multicolumn{2}{|c|}{$\begin{array}{l}\text { OLS Model with No } \\
\text { Control for Wage at } \\
\text { Age } 20 / 21\end{array}$} & \multicolumn{2}{|c|}{$\begin{array}{l}\text { OLS Model Including } \\
\text { Control for Wage at } \\
\text { Age } 20 / 21\end{array}$} & \multicolumn{2}{|c|}{$\begin{array}{c}\text { Differenced Model: } \\
\text { Wage Minus Wage at } \\
\text { Age } 20 / 21\end{array}$} & \multicolumn{2}{|c|}{$\begin{array}{c}\text { Quasi-Differenced Model: } \\
\text { Wage Minus } 2.62 \text { x Wage at } \\
\text { Age } 20 / 21\end{array}$} \\
\hline & & $\begin{array}{l}\text { Conscription } \\
\text { Effect } \\
\text { (1) }\end{array}$ & $\begin{array}{l}\text { Std. } \\
\text { Error } \\
(2)\end{array}$ & $\begin{array}{l}\text { Conscription } \\
\text { Effect } \\
\text { (3) }\end{array}$ & $\begin{array}{l}\text { Std. } \\
\text { Error } \\
(4)\end{array}$ & $\begin{array}{l}\text { Conscription } \\
\text { Effect } \\
\text { (5) }\end{array}$ & $\begin{array}{l}\text { Std. } \\
\text { Error } \\
(6)\end{array}$ & $\begin{array}{l}\text { Conscription } \\
\text { Effect } \\
\text { (7) }\end{array}$ & $\begin{array}{l}\text { Std. } \\
\text { Error } \\
(8)\end{array}$ \\
\hline 1991 & 24 & -1.4 & $(1.1)$ & -1.8 & $(1.0)$ & -2.1 & (1.1) & -3.1 & $(2.0)$ \\
\hline 1992 & 25 & 1.7 & $(1.2)$ & 1.4 & (1.1) & 1.0 & (1.2) & 0.0 & (2.1) \\
\hline 1993 & 26 & 1.5 & (1.3) & 1.4 & $(1.2)$ & 1.3 & (1.3) & 1.1 & (2.3) \\
\hline 1994 & 27 & 1.2 & (1.4) & 1.1 & (1.3) & 0.9 & (1.4) & 0.5 & (2.4) \\
\hline 1995 & 28 & 1.8 & (1.3) & 1.5 & (1.2) & 1.1 & (1.3) & 0.0 & (2.3) \\
\hline 1996 & 29 & 2.6 & (1.4) & 2.2 & (1.4) & 1.7 & (1.5) & 0.3 & (2.5) \\
\hline 1997 & 30 & 0.6 & (1.3) & 0.6 & (1.3) & 0.6 & (1.4) & 0.6 & (2.4) \\
\hline 1998 & 31 & 1.4 & (1.3) & 1.0 & (1.2) & 0.5 & (1.4) & -0.8 & (2.4) \\
\hline 1999 & 32 & 0.9 & (1.3) & 0.6 & $(1.2)$ & 0.1 & (1.3) & -1.1 & (2.3) \\
\hline 2000 & 33 & 1.2 & (1.3) & 1.2 & (1.3) & 1.0 & (1.4) & 0.7 & (2.3) \\
\hline 2002 & 35 & 0.8 & (1.4) & 0.9 & (1.4) & 0.9 & $(1.5)$ & 1.0 & (2.4) \\
\hline 2003 & 36 & 2.2 & (1.4) & 2.3 & (1.4) & 2.4 & (1.5) & 2.8 & (2.5) \\
\hline 2004 & 37 & 0.4 & (1.4) & 0.6 & (1.4) & 0.9 & (1.5) & 1.7 & (2.5) \\
\hline 2005 & 38 & 2.2 & (1.4) & 2.1 & (1.4) & 2.0 & (1.5) & 1.6 & (2.4) \\
\hline 2006 & 39 & 3.0 & (1.5) & 2.8 & (1.4) & 2.6 & (1.5) & 1.8 & (2.4) \\
\hline 2007 & 40 & 3.7 & (1.5) & 3.5 & (1.4) & 3.1 & (1.5) & 2.2 & (2.4) \\
\hline 2008 & 41 & 2.5 & (1.4) & 2.4 & (1.4) & 2.2 & (1.5) & 1.8 & (2.5) \\
\hline 2009 & 42 & 1.7 & (1.5) & 1.8 & (1.5) & 2.1 & (1.6) & 2.7 & (2.5) \\
\hline \multicolumn{2}{|c|}{ Pooled 1991-2000 } & 1.1 & $(0.9)$ & 0.9 & $(0.8)$ & 0.6 & (0.9) & -0.2 & (2.0) \\
\hline \multicolumn{2}{|c|}{ Pooled 2002-2009 } & 2.1 & (1.2) & 2.1 & (1.2) & 2.0 & (1.3) & 1.9 & (2.3) \\
\hline
\end{tabular}

Notes: Estimated coefficients times 100 (with standard errors in parentheses) from models fit separately by age to wages of conscripts and non-conscripts. All models include dummies for education as of age 20 or 21. Models in columns 3-4 include wage measured at age 20 or 21 . Models in columns 5-6 use as dependent variable wage at indicated age, minus wage at age 20/21. Models in columns 7-8 use as dependent variable wage at indicated age minus 2.62 times wage at age 20/21. Pooled estimates use sample of available person-year observations, and include year dummies. Standard errors for pooled models are clustered by person. Source: Portugal, MTSS (1986-2009). 
Table A2.b: Estimated Wage Effects of Conscription at Various Ages from Alternative Models for LoW-Education Men

\begin{tabular}{|c|c|c|c|c|c|c|c|c|c|}
\hline \multirow[b]{2}{*}{ Year } & \multirow{2}{*}{$\begin{array}{l}\text { Modal } \\
\text { Age }\end{array}$} & \multicolumn{2}{|c|}{$\begin{array}{l}\text { OLS Model with No } \\
\text { Control for Wage at } \\
\text { Age } 20 / 21\end{array}$} & \multicolumn{2}{|c|}{$\begin{array}{l}\text { OLS Model Including } \\
\text { Control for Wage at } \\
\text { Age } 20 / 21\end{array}$} & \multicolumn{2}{|c|}{$\begin{array}{c}\text { Differenced Model: } \\
\text { Wage Minus Wage at } \\
\text { Age } 20 / 21\end{array}$} & \multicolumn{2}{|c|}{$\begin{array}{c}\text { Quasi-Differenced Model: } \\
\text { Wage Minus } 2.62 \text { x Wage at } \\
\text { Age } 20 / 21\end{array}$} \\
\hline & & $\begin{array}{l}\text { Conscription } \\
\text { Effect } \\
\text { (1) }\end{array}$ & $\begin{array}{l}\text { Std. } \\
\text { Error } \\
(2)\end{array}$ & $\begin{array}{l}\text { Conscription } \\
\text { Effect } \\
\text { (3) }\end{array}$ & $\begin{array}{l}\text { Std. } \\
\text { Error } \\
(4)\end{array}$ & $\begin{array}{l}\text { Conscription } \\
\text { Effect } \\
\text { (5) }\end{array}$ & $\begin{array}{l}\text { Std. } \\
\text { Error } \\
(6)\end{array}$ & $\begin{array}{l}\text { Conscription } \\
\text { Effect } \\
\text { (7) }\end{array}$ & $\begin{array}{l}\text { Std. } \\
\text { Error } \\
(8)\end{array}$ \\
\hline 1991 & 24 & -1.4 & (1.5) & -1.7 & (1.4) & -1.9 & (1.5) & -2.8 & (2.8) \\
\hline 1992 & 25 & -0.8 & (1.5) & -1.0 & (1.5) & -1.4 & (1.6) & -2.3 & (3.0) \\
\hline 1993 & 26 & 0.1 & (1.8) & 0.7 & (1.7) & 1.0 & (1.8) & 2.0 & (3.1) \\
\hline 1994 & 27 & 0.9 & (1.9) & 0.9 & (1.8) & 0.9 & (1.9) & 0.7 & (3.3) \\
\hline 1995 & 28 & 1.0 & (1.7) & 1.1 & (1.6) & 1.2 & (1.8) & 1.6 & (3.2) \\
\hline 1996 & 29 & 3.1 & (2.0) & 2.8 & (1.9) & 2.7 & (2.1) & 2.0 & (3.4) \\
\hline 1997 & 30 & -0.7 & (1.8) & -0.6 & (1.7) & -0.5 & (1.9) & -0.1 & (3.2) \\
\hline 1998 & 31 & 0.5 & (1.7) & 0.7 & (1.6) & 1.2 & (1.8) & 2.4 & (3.2) \\
\hline 1999 & 32 & 2.0 & (1.7) & 2.1 & (1.6) & 2.3 & (1.8) & 2.8 & (3.2) \\
\hline 2000 & 33 & 1.7 & (1.7) & 1.9 & (1.6) & 2.1 & (1.8) & 2.6 & (3.1) \\
\hline 2002 & 35 & 2.9 & (1.8) & 3.1 & (1.8) & 3.4 & (1.9) & 4.1 & (3.3) \\
\hline 2003 & 36 & 4.2 & (1.9) & 4.6 & (1.8) & 5.5 & (2.0) & 7.5 & (3.4) \\
\hline 2004 & 37 & 2.3 & (1.8) & 2.6 & (1.8) & 3.3 & (2.0) & 5.0 & (3.4) \\
\hline 2005 & 38 & 3.6 & (1.9) & 3.6 & (1.8) & 3.6 & (2.0) & 3.5 & (3.4) \\
\hline 2006 & 39 & 4.1 & (1.8) & 3.9 & (1.8) & 3.4 & (2.0) & 2.4 & (3.4) \\
\hline 2007 & 40 & 5.0 & (1.9) & 4.9 & (1.8) & 4.8 & (2.0) & 4.4 & (3.4) \\
\hline 2008 & 41 & 5.5 & (1.8) & 5.4 & (1.8) & 5.2 & (2.0) & 4.7 & (3.4) \\
\hline 2009 & 42 & 4.8 & (1.8) & 4.8 & (1.8) & 4.9 & (2.0) & 5.0 & (3.5) \\
\hline \multicolumn{2}{|c|}{ Pooled 1991-2000 } & 0.6 & $(1.2)$ & 0.6 & (1.1) & 0.7 & (1.3) & 0.8 & (2.7) \\
\hline \multicolumn{2}{|c|}{ Pooled 2002-2009 } & 4.1 & (1.7) & 4.1 & (1.6) & 4.3 & (1.8) & 4.5 & (3.2) \\
\hline
\end{tabular}

Notes: Estimated coefficients times 100 (with standard errors in parentheses) from models fit separately by age to wages of conscripts and non-conscripts. All models include dummies for education as of age 20 or 21. Models in columns 3-4 include wage measured at age 20 or 21 . Models in columns 5-6 use as dependent variable wage at indicated age, minus wage at age 20/21. Models in columns 7-8 use as dependent variable wage at indicated age minus 2.62 times wage at age 20/21. Pooled estimates use sample of available person-year observations, and include year dummies. Standard errors for pooled models are clustered by person. Source: Portugal, MTSS (1986-2009). 
TAble A2.c: Estimated Wage Effects of Conscription at Various Ages from Alternative Models for High-Education Men

\begin{tabular}{|c|c|c|c|c|c|c|c|c|c|}
\hline \multirow[b]{2}{*}{ Year } & \multirow{2}{*}{$\begin{array}{l}\text { Modal } \\
\text { Age }\end{array}$} & \multicolumn{2}{|c|}{$\begin{array}{l}\text { OLS Model with No } \\
\text { Control for Wage at } \\
\text { Age } 20 / 21\end{array}$} & \multicolumn{2}{|c|}{$\begin{array}{l}\text { OLS Model Including } \\
\text { Control for Wage at } \\
\text { Age } 20 / 21\end{array}$} & \multicolumn{2}{|c|}{$\begin{array}{c}\text { Differenced Model: } \\
\text { Wage Minus Wage at } \\
\text { Age } 20 / 21\end{array}$} & \multicolumn{2}{|c|}{$\begin{array}{c}\text { Quasi-Differenced Model: } \\
\text { Wage Minus } 2.62 \text { x Wage at } \\
\text { Age } 20 / 21\end{array}$} \\
\hline & & $\begin{array}{l}\text { Conscription } \\
\text { Effect } \\
\text { (1) }\end{array}$ & $\begin{array}{l}\text { Std. } \\
\text { Error } \\
(2)\end{array}$ & $\begin{array}{l}\text { Conscription } \\
\text { Effect } \\
\text { (3) }\end{array}$ & $\begin{array}{l}\text { Std. } \\
\text { Error } \\
\text { (4) }\end{array}$ & $\begin{array}{l}\text { Conscription } \\
\text { Effect } \\
\text { (5) }\end{array}$ & $\begin{array}{l}\text { Std. } \\
\text { Error } \\
(6)\end{array}$ & $\begin{array}{l}\text { Conscription } \\
\text { Effect } \\
\text { (7) }\end{array}$ & $\begin{array}{l}\text { Std. } \\
\text { Error } \\
(8)\end{array}$ \\
\hline 1991 & 24 & -1.4 & (1.6) & -1.8 & (1.4) & -2.2 & (1.5) & -3.4 & (2.9) \\
\hline 1992 & 25 & 3.7 & (1.8) & 3.4 & (1.7) & 3.0 & (1.8) & 1.8 & (3.2) \\
\hline 1993 & 26 & 2.3 & (1.9) & 2.0 & (1.8) & 1.6 & (2.0) & 0.3 & (3.4) \\
\hline 1994 & 27 & 1.5 & (1.9) & 1.2 & (2.0) & 1.0 & (2.1) & 0.2 & (3.5) \\
\hline 1995 & 28 & 2.5 & (1.9) & 1.8 & (1.8) & 1.0 & (1.9) & -1.5 & (3.4) \\
\hline 1996 & 29 & 2.2 & (2.0) & 1.6 & (1.9) & 1.0 & (2.1) & -1.1 & (3.5) \\
\hline 1997 & 30 & 1.7 & (2.0) & 1.6 & (1.9) & 1.5 & (2.0) & 1.2 & (3.5) \\
\hline 1998 & 31 & 2.0 & (1.9) & 1.1 & (1.9) & 0.0 & (2.0) & -3.3 & (3.4) \\
\hline 1999 & 32 & -0.1 & (1.9) & -0.7 & (1.8) & -1.6 & (2.0) & -4.1 & (3.4) \\
\hline 2000 & 33 & 0.9 & (1.9) & 0.6 & (1.9) & 0.3 & (2.0) & -0.7 & (3.4) \\
\hline 2002 & 35 & -0.8 & (2.1) & -1.0 & (2.0) & -1.1 & (2.2) & -1.5 & (3.5) \\
\hline 2003 & 36 & 0.5 & (2.1) & 0.3 & (2.0) & 0.0 & (2.2) & -0.9 & (3.7) \\
\hline 2004 & 37 & -1.0 & (2.2) & -1.0 & (2.1) & -1.0 & (2.3) & -0.9 & (3.6) \\
\hline 2005 & 38 & 1.1 & (2.1) & 1.0 & (2.1) & 0.8 & $(2.2)$ & 0.2 & (3.5) \\
\hline 2006 & 39 & 2.2 & (2.2) & 2.0 & (2.1) & 1.9 & (2.2) & 1.4 & (3.5) \\
\hline 2007 & 40 & 2.7 & (2.2) & 2.3 & (2.1) & 1.8 & (2.2) & 0.5 & (3.5) \\
\hline 2008 & 41 & 0.2 & (2.2) & 0.1 & (2.1) & -0.1 & (2.3) & -0.4 & (3.6) \\
\hline 2009 & 42 & -0.6 & (2.3) & -0.4 & (2.2) & 0.0 & (2.3) & 1.0 & (3.6) \\
\hline \multicolumn{2}{|c|}{ Pooled 1991-2000 } & 1.5 & (1.3) & 1.0 & (1.2) & 0.5 & (1.4) & -1.1 & (2.8) \\
\hline \multicolumn{2}{|c|}{ Pooled 2002-2009 } & 0.5 & (1.8) & 0.4 & (1.7) & 0.3 & (1.9) & -0.1 & (3.1) \\
\hline
\end{tabular}

Notes: Estimated coefficients times 100 (with standard errors in parentheses) from models fit separately by age to wages of conscripts and non-conscripts. All models include dummies for education as of age 20 or 21. Models in columns 3-4 include wage measured at age 20 or 21 . Models in columns 5-6 use as dependent variable wage at indicated age, minus wage at age 20/21. Models in columns 7-8 use as dependent variable wage at indicated age minus 2.62 times wage at age 20/21. Pooled estimates use sample of available person-year observations, and include year dummies. Standard errors for pooled models are clustered by person. Source: Portugal, MTSS (1986-2009). 
Figure A.1: Age Profiles of Hourly Wages, Cohort 1967, Females

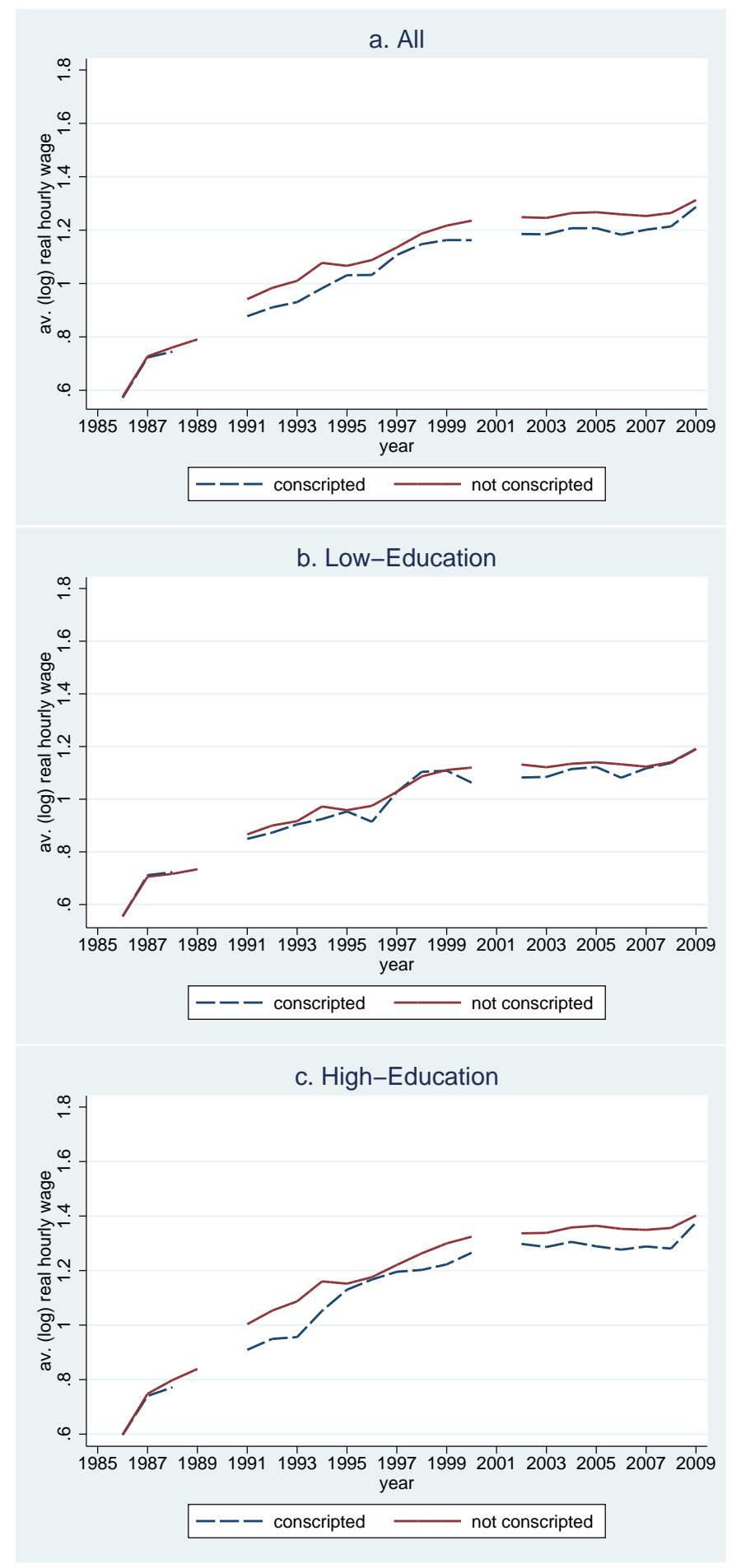

Note: 'Conscripted' is an individual working full-time in 1987 or 1988 and reported on leave during the years military enlistment is due; 'non-conscripted' is an individual observed working full-time during the years military enlistment is due. For the cohort born 1967, military enlistment was due the year the individual turned 21 and it lasted for 24 months. Source: Computations based on Portugal, MTSS (1986-2009). 
Figure A.2: Age Profiles of Employment, Cohort 1967, Females

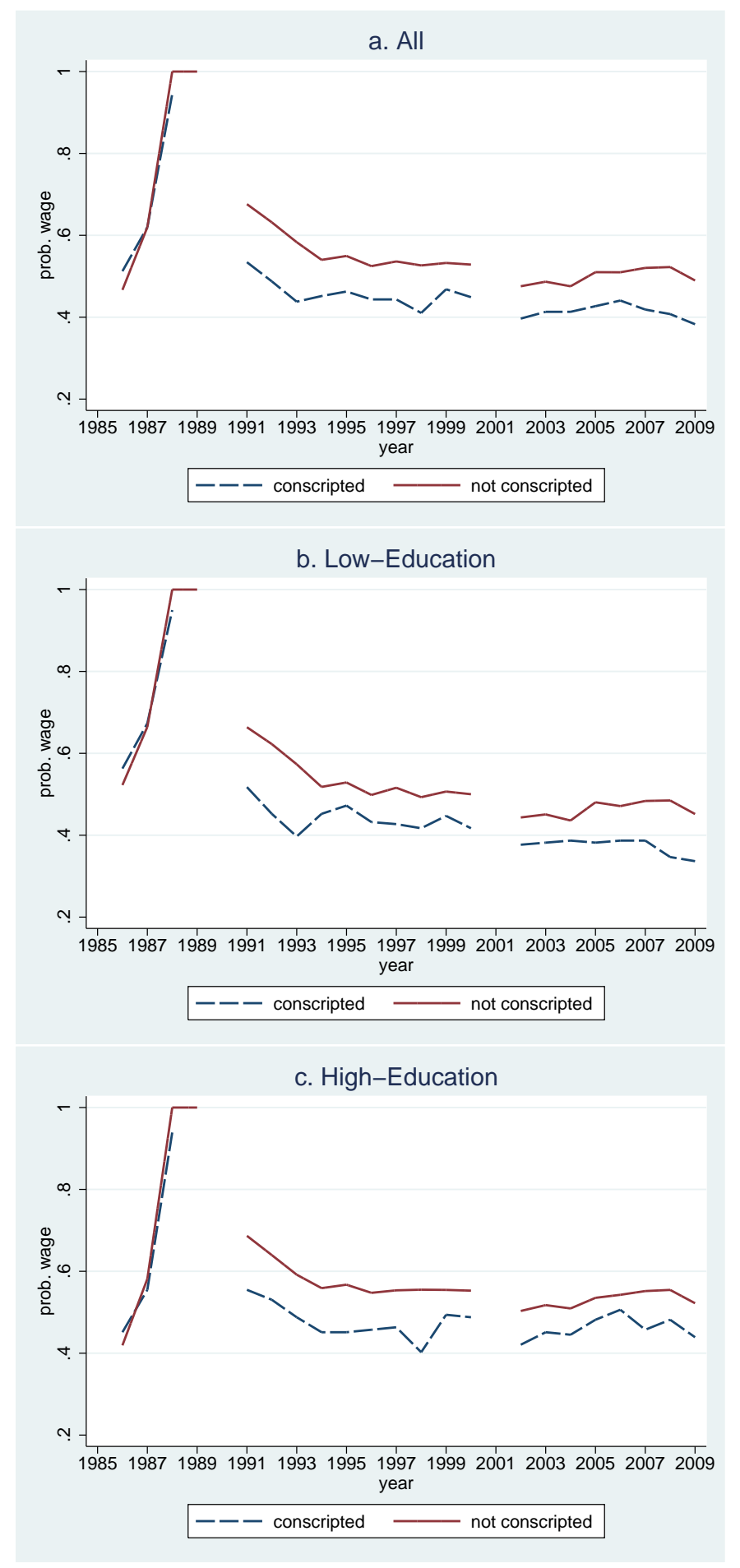

Note: 'Conscripted' is an individual working full-time in 1987 or 1988 and reported on leave during the years military enlistment is due; 'non-conscripted' is an individual observed working full-time during the years military enlistment is due. For the cohort born 1967, military enlistment was due the year the individual turned 21 and it lasted for 24 months. Source: Computations based on Portugal, MTSS (1986-2009). 

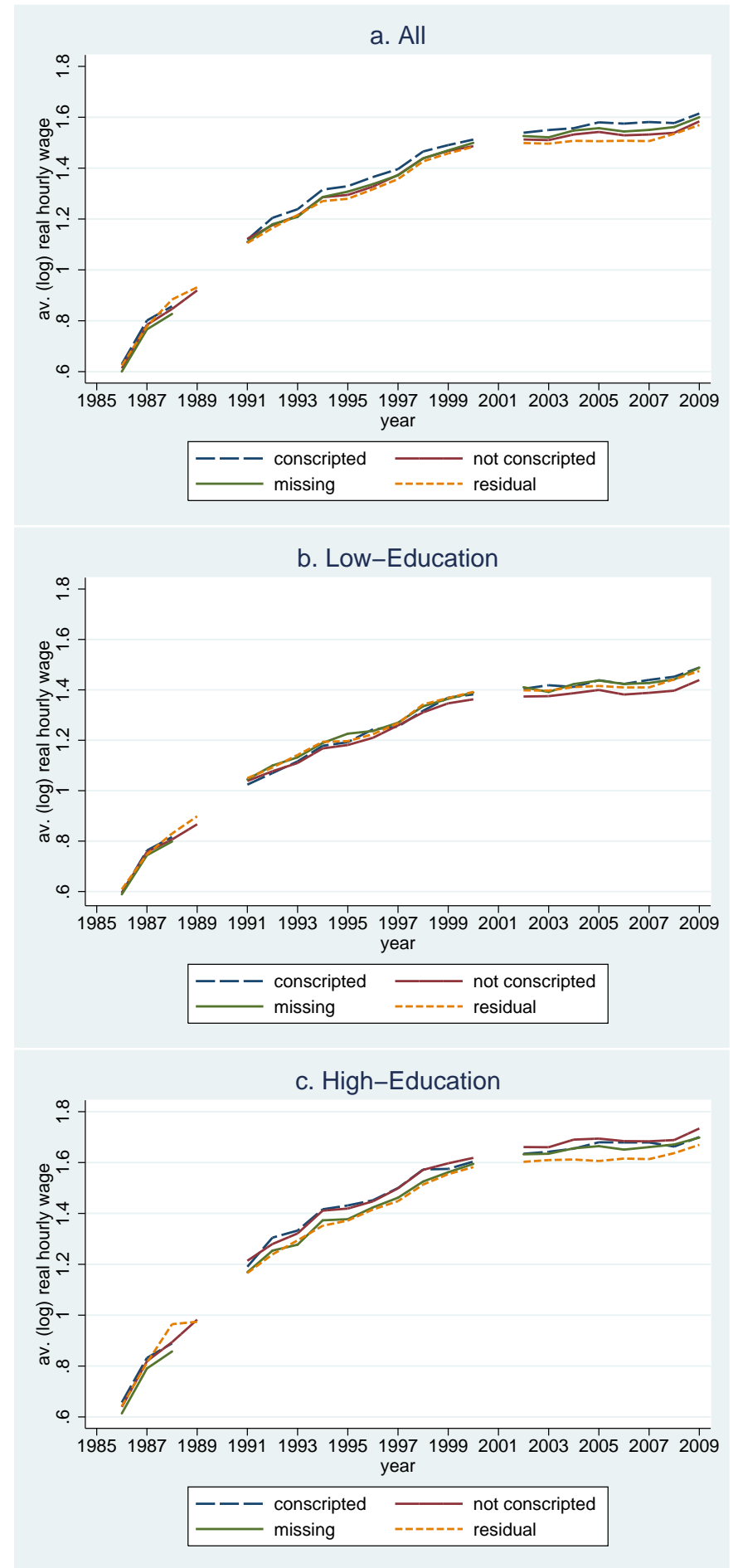

Note: Conscripted is an individual working full-time in 1987 or 1988 and reported on leave during the years military enlistment is due; non-conscripted is an individual observed working full-time during the years military enlistment would have been due; 'missing' is an individual not observed employed in the private sector during the years military conscription was due; the 'residual' category combines all other combinations of labor market situations from 1987 to 1989. For the cohort born 1967, military enlistment was due the year the individual turned 21 and it lasted for 24 months. Source: Computations based on Portugal, MTSS (1986-2009). 


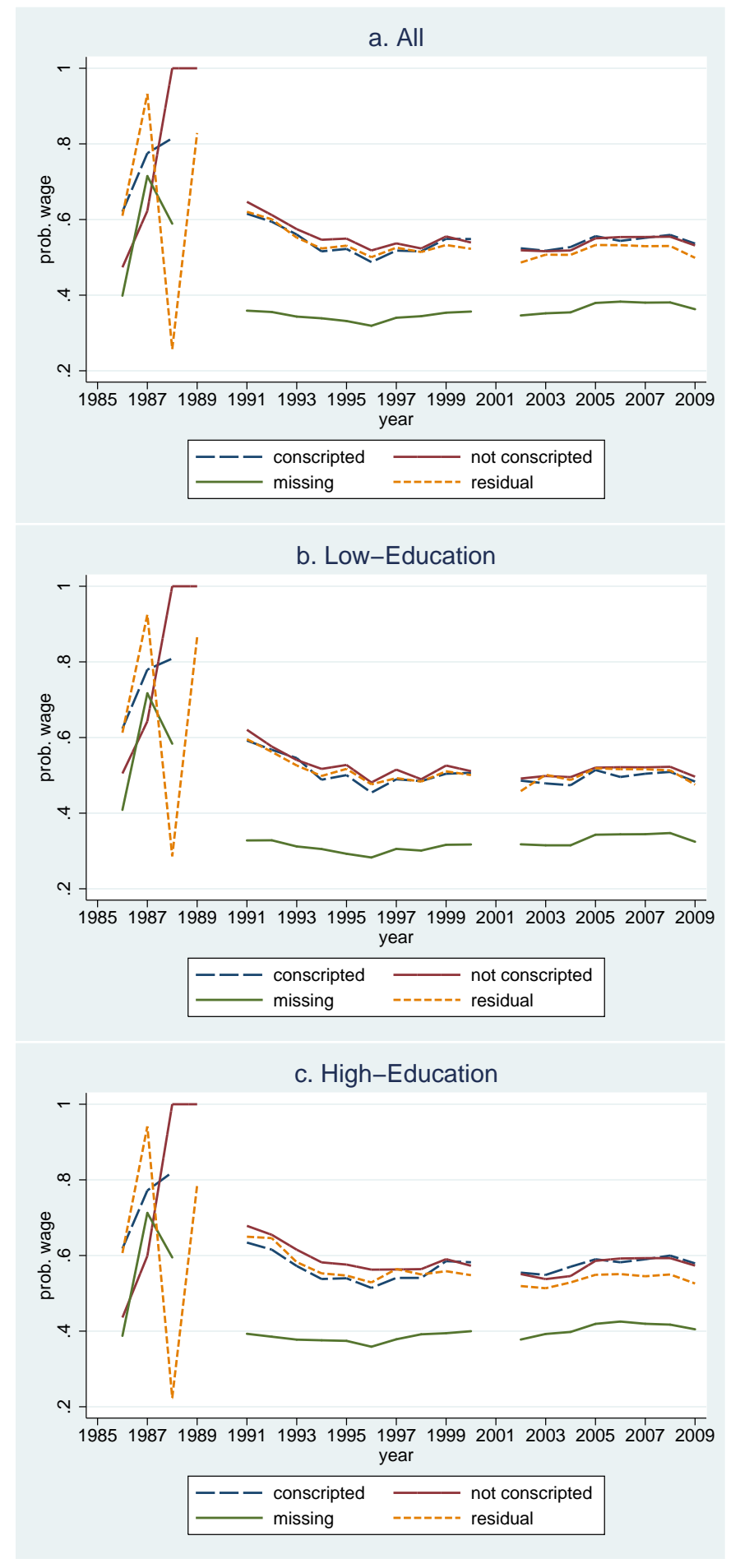

Note: Conscripted is an individual working full-time the year before military enlistment is due, and reported on leave during the years military enlistment is due; non-conscripted is an individual observed working full-time during the years military enlistment would have been due; 'missing' is an individual not observed employed in the private sector during the years military conscription was due; the 'residual' category combines all other combinations of labor market situations from 1987 to 1989 . For the cohort born 1967, military enlistment was due the year the individual turned 21 and it lasted for 24 months. Source: Computations based on Portugal, MTSS (1986-2009). 